\title{
El nuevo Estatuto de Andalucía y la financiación autonómica
}

\author{
Francisco Adame Martínez \\ Profesor Titular de Derecho Financiero y Tributario \\ Universidad de Sevilla
}

\begin{abstract}
SUMARIO: 1. INTRODUCCIÓN. 2. EL PROCESO DE APROBACIÓN DEL SISTEMA DE FINANCIACIÓN Y SU VOCACIÓN DE ESTABILIDAD. 3. FUENTES DE FINANCIACIÓN DE LAS COMUNIDADES AUTÓNOMAS. 4. LOS IMPUESTOS CEDIDOS COMO INSTRUMENTOS DE CORRESPONSABILIDAD FISCAL: DE LA CESIÓN DE RECAUDACIÓN A LA CESIÓN DE COMPETENCIAS NORMATIVAS. 5. PROBLEMAS DE COMPETENCIA FISCAL ENTRE COMUNIDADES AUTÓNOMAS EN RELACIÓN CON EL IMPUESTO SOBRE SUCESIONES Y DONACIONES. 6. EL PAPEL DE LOS IMPUESTOS PROPIOS EN EL SISTEMA DE FINANCIACIÓN. LA HABILITACIÓN DE ESPACIOS FISCALES PROPIOS PARA LAS COMUNIDADES AUTÓNOMAS. 7. OTRAS NOVEDADES DEL ESTATUTO ANDALUZ EN MATERIA DE FINANCIACIÓN AUTONÓMICA. 8. CONSIDERACIONES SOBRE LA "DEUDA HISTÓRICA" A LA LUZ DE LA SENTENCIA DEL TRIBUNAL CONSTITUCIONAL 13/2007
\end{abstract}

\section{INTRODUCGIÓN}

El actual sistema de financiación de las Comunidades Autónomas de régimen común que está vigente desde el 1 de enero de 2002, fue aprobado por unanimidad en el Consejo de Política Fiscal y Financiera en su sesión de 27 de julio de 2001 y posteriormente aceptado por cada Comunidad Autónoma en las correspondientes Comisiones Mixtas bilaterales Estado-Comunidad Autónoma, que se celebraron en el primer trimestre del año 2002. En este epígrafe introductorio comentaremos brevemente las principales normas reguladoras de dicho sistema.

La regulación básica se contiene, en primer lugar, en la Constitución española, concretamente en sus artículos 156 a 158. En el artículo 156 se recogen los tres principios o pilares básicos que han de inspirar cualquier modelo de financiación autonómica: autonomía financiera, solidaridad y coordina- 
ción. Junto a estos tres principios constitucionales hay que mencionar otro que aparece en los nuevos Estatutos de Autonomía que ya se han aprobado (Cataluña, Andalucía y Valencia), así como en diversos pronunciamientos del Tribunal Constitucional sobre cuestiones relacionadas con la financiación autonómica. Nos referimos al principio de responsabilidad fiscal, que tiene su origen en la teoría del federalismo fiscal y conforme al cual los entes territoriales no sólo son responsables ante sus ciudadanos de las decisiones en materia de gasto, sino también de las decisiones en materia de ingresos.

El artículo 157 contiene una enumeración de los recursos con los que se financiarán estos entes territoriales. Allí se mencionan, entre otros, los impuestos cedidos, sus propios tributos, participaciones en los ingresos del Estado, rendimientos procedentes de su patrimonio e ingresos de derecho privado y el producto de sus operaciones de crédito. Se trata de una enumeración no cerrada sino abierta, circunstancia que responde a que en el momento en que se aprobó la Constitución no se sabía cuál iba a ser el resultado final del proceso histórico de descentralización política que se inició con su aprobación. Si ni siquiera se sabía cuántas Comunidades Autónomas se constituirían, cómo se iba a regular con detalle su sistema de financiación.

El artículo 158 está consagrado al principio de solidaridad, y en él se contempla la creación de un Fondo de Compensación para hacer efectivo dicho principio y corregir los desequilibrios económicos interterritoriales, así como la posibilidad de establecer en los Presupuestos Generales del Estado una asignación a las Comunidades Autónomas en función del volumen de los servicios y actividades estatales que hayan asumido y de la garantía de un nivel mínimo en la prestación de los servicios públicos fundamentales en todo el territorio español.

Como veremos después algunas Comunidades Autónomas han establecido en sus respectivos estatutos de autonomía disposiciones que se amparan en este precepto con el fin de obtener recursos adicionales del Estado. En el caso concreto de Andalucía la reclamación de la llamada deuda histórica tiene su fundamento en esta norma y en la disposición adicional segunda tanto del primitivo Estatuto como del recientemente aprobado. Precisamente, los Estatutos de Autonomía constituyen la segunda norma básica en materia de financiación autonómica. No nos extendemos ahora en esta cuestión porque después examinaremos el contenido de los preceptos que el nuevo Estatuto de Autonomía de Andalucía dedica a la cuestión de la financiación.

Para desarrollar el contenido de los preceptos constitucionales antes citados se aprobó la Ley Orgánica 8/1980, de 22 de septiembre, de Financia- 
ción de las Comunidades Autónomas (en adelante LOFCA), que forma parte del bloque de la constitucionalidad en la cuestión que estamos estudiando. Esta Ley tampoco concretó cuál debía ser la contribución relativa de cada una de las fuentes de ingresos a la financiación de estos entes territoriales. Como después comentaremos la LOFCA fue modificada por la Ley Orgánica 3/1996, de 27 de diciembre, que introdujo importantes cambios a fin de hacer posible la cesión parcial del Impuesto sobre la Renta de las Personas Físicas y la atribución a las Comunidades Autónomas de competencias normativas con ciertos límites en relación con los impuestos que ya habían sido cedidos con anterioridad.

En este breve repaso por las normas básicas que regulan la financiación de las Comunidades Autónomas en la actualidad debemos citar finalmente la Ley 21/2001, de 27 diciembre, por la que se regulan las medidas fiscales y administrativas del nuevo sistema de financiación, en la que se recoge el contenido del Acuerdo del Consejo de Política Fiscal y Financiera de 27 de julio de 2001, antes citado, con las modificaciones introducidas en las reuniones del Pleno de dicho Consejo de 16 y 22 de noviembre de 2001, y la Ley 22/2001, de 27 de diciembre, reguladora de los Fondos de Compensación Interterritorial. Estas normas fueron aprobadas para poner en marcha las principales novedades introducidas en la financiación de estos entes territoriales en 2001. Después comentaremos algunos aspectos concretos de la Ley 21/2001.

\section{EL PROCESO DE APROBACIÓN DEL SISTEMA DE FINANCIA- CIÓN Y SU VOCACIÓN DE ESTABILIDAD}

Como ya se ha avanzado en el apartado anterior la Constitución española no diseñó un sistema de financiación rígido sino que otorgó, en consonancia con ese carácter abierto del modelo de Estado, un amplio margen de elección al legislador a fin de concretar cómo debían financiarse estos entes territoriales. Como ha destacado la doctrina, al margen de sus defectos ese carácter abierto del sistema ha permitido y sin duda permitirá también en el futuro alcanzar cotas nada desdeñables de acuerdo político entre las administraciones implicadas.

Tanto el sistema de financiación de las Comunidades Autónomas de régimen común vigente desde 2002 como los anteriores han nacido de un pacto político entre el Estado y estos entes territoriales. Y ese pacto es el resultado de una negociación política que se ha llevado siempre a cabo en dos fases. 
La primera fase consiste en una negociación multilateral que se desarrolla en el Consejo de Política Fiscal y Financiera, que es un órgano al que inicialmente se atribuyó un carácter "consultivo y de deliberación”, en el que están representados el Estado y las Comunidades Autónomas. Tras la reforma de la LOFCA por la Ley Orgánica 5/2001 que introdujo nuevas normas de estabilidad presupuestaria, el Consejo de Política Fiscal y Financiera pasó a configurarse como un órgano de "coordinación". A la vista de su naturaleza, las decisiones de este organismo no deberían pasar de ser meras recomendaciones sin valor normativo alguno. Sin embargo, en los modelos de financiación anteriores al actualmente vigente las sucesivas Leyes de Presupuestos Generales del Estado se limitaban a remitirse a las reglas previstas en los Acuerdos de dicho Consejo. Pero desde el año 2001, fecha en la que se aprobó el actual modelo de financiación en el Consejo de Política Fiscal y Financiera, las normas básicas del modelo de financiación figuran en una Ley específica aprobada por las Cortes Generales, como es la Ley 21/2001, antes citada. A esta cuestión se refiere el Informe sobre la reforma del sistema de financiación autonómica, emitido por la Comisión para el estudio y propuesta de un nuevo sistema de financiación de las Comunidades Autónomas aplicable a partir de 2002. Esta Comisión fue creada por la Secretaría de Estado de Hacienda en septiembre de 2000 cuando se inició el debate para la aprobación de un nuevo modelo que debería entrar en vigor a partir de 1 de enero de 2002. Dicha Comisión, integrada por representantes del Ministerio de Hacienda y diversos profesores universitarios, dejó bien claro en su Informe que no podía otorgarse a los acuerdos del Consejo carácter de norma jurídica que vincule o limite las decisiones legislativas de las Cortes Generales, porque un órgano consultivo, deliberante o de coordinación carece de potestad legislativa. En este sentido, la Comisión concluyó lo siguiente: "Y precisamente por ello insistimos en una circunstancia que consideramos clave a la hora de diseñar y aprobar el nuevo sistema de financiación autonómica: los acuerdos del Consejo de Política Fiscal y Financiera deben someterse a las decisiones legislativas que sobre el sistema deben adoptar las Cortes Generales. Son ellas quienes deben debatir, enmendar y aprobar las normas legales que articulan el nuevo de sistema de financiación autonómica. Esto es así en nuestro Estado de Derecho (...) La modificación del sistema de financiación exige ley orgánica, de forma que pretender establecer un modelo con relevancia paccionada, en el que la ley orgánica es una mera consecuencia del acuerdo previo de un órgano consultivo constituye una grave quiebra del esquema constitucional".

La segunda fase de la negociación tiene excepcional importancia puesto que para que el modelo aprobado por el Consejo y cuyo contenido se incluye en una Ley ordinaria resulte aplicable a una Comunidad Autónoma es preci- 
so que ésta lo acepte en su respectiva Comisión Mixta. Las Comisiones Mixtas son órganos bilaterales de relación entre el Estado y la Comunidad Autónoma que se crearon con la finalidad de garantizar la financiación de los servicios que el Estado iría transfiriendo a las Comunidades Autónomas. Nacieron pues con una clara vocación de temporalidad, tal como lo demuestra el hecho de que aparecieran reguladas en la disposición transitoria primera de la LOFCA. Por ello, estos órganos tal vez deberían haber desaparecido una vez concluido el llamado período transitorio, que marcó el tránsito desde un Estado con administración centralizada a una Estado descentralizado desde el punto de vista financiero y político y que abarcó hasta 1986. Sin embargo, las Comisiones Mixtas no sólo no han desaparecido sino que incluso han ido adquiriendo cada vez mayor relevancia en las negociaciones para la aplicación del sistema de financiación. En efecto, se han consolidado como órganos imprescindibles para que las Comunidades Autónomas puedan negociar por separado con el Estado, de manera que mientras que las Comunidades Autónomas no den su conformidad en su respectiva Comisión Mixta el modelo acordado por el Consejo de Política Fiscal y Financiera no se les aplicará. Esto es lo que ocurrió por ejemplo con los representantes de las Comunidades de Andalucía, Extremadura y Castilla-La Mancha que se opusieron en sus respectivas Comisiones Mixtas a la aplicación del sistema de financiación aprobado por el Consejo de Política Fiscal para el período 1997-2001, lo que determinó que estas Comunidades Autónomas siguieran rigiéndose por el modelo aprobado para el período 1992-1996.

La posibilidad de que alguna Comunidad Autónoma se niegue a aprobar o aplicar el sistema de financiación fue una cuestión sobre la que también se pronunció en su Informe la Comisión para el estudio y propuesta de un nuevo sistema de financiación aplicable a partir de 2002. En opinión de la Comisión "no cabe que las Comunidades Autónomas puedan oponer un rechazo total al modelo de financiación aprobado de conformidad con las leyes aprobadas por las Cortes Generales en desarrollo de las previsiones constitucionales". Otro asunto distinto es, según la Comisión, "lo que ocurre en el ámbito de una de las piezas claves del sistema de financiación autonómica: los tributos cedidos por el Estado". Cuando se trata de las leyes de cesión de tributos, y así lo ha reconocido el Tribunal Supremo en su Sentencia de 29 de enero de 1999, nos encontramos ante "una modalidad de leyes paccionadas, que ha surgido como consecuencia del establecimiento por la Constitución de las Comunidades Autónomas, leyes que antes de la elaboración del correspondiente proyecto de ley exigen con carácter previo y necesario el acuerdo entre el Estado y las Comunidades Autónomas sobre las materias a regular...”. En el fondo, concluye diciendo la Comisión, en relación con los tributos cedidos, quiérase o no "nos 
encontramos ante una materia que, amén de formar parte del modelo de financiación, implica también la transferencia de competencias en ese ámbito financiero, y en cuanto tal transferencia es indudable la necesaria aquiescencia de la Comunidad Autónoma destinataria de la misma". Y dicha aquiescencia debe producirse en el seno de la Comisión Mixta Estado-Comunidad Autónoma.

El nuevo Estatuto de Andalucía dedica su artículo 184 a la regulación de la composición y funciones de esta Comisión que ahora pasa a llamarse Comisión Mixta de Asuntos Económicos y Fiscales Estado-Comunidad Autónoma. Entre sus funciones se pueden destacar la concreción, aprobación, actualización y el seguimiento del sistema de financiación, así como la canalización del conjunto de relaciones fiscales y financieras de la Comunidad Autónoma y el Estado; acordar el alcance y condiciones de la cesión de tributos de titularidad estatal; establecer los mecanismos de colaboración entre la Administración Tributaria de Andalucía y la Administración Tributaria del Estado, así como los criterios de coordinación y armonización fiscal de acuerdo con las características o naturaleza de los tributos cedidos; negociar el porcentaje de participación de Andalucía en la distribución territorial de los fondos estructurales europeos, así como estudiar las inversiones que el Estado realizará en Andalucía. Sobre este último tema volveremos más adelante cuando comentemos la disposición relativa a la famosa "deuda histórica".

Para respetar la posición del Consejo de Política Fiscal y Financiera en el proceso de aprobación del sistema de financiación este precepto del Estatuto añade al final de su apartado 1 que todas esas funciones las ejercerá la Comisión Mixta "sin perjuicio de los acuerdos suscritos por la Junta de Andalucía en esta materia en instituciones y organismos de carácter multilateral”.

Una de las características básicas de los modelos de financiación de las Comunidades Autónomas vigentes hasta finales de 2001 era que los mismos no resultaban aplicables indefinidamente sino que tenían una vigencia temporal determinada. Hasta esa fecha, los modelos que se aprobaron tenían una vigencia de cinco años. Precisamente la primera cuestión que se le formuló a la Comisión para el estudio y propuesta de un nuevo sistema de financiación de las Comunidades Autónomas aplicable a partir de 2002, antes citada, fue que expresara su opinión sobre el fundamento normativo de la aprobación quinquenal del modelo de financiación autonómica y sobre la posibilidad de que se aprobase un modelo de financiación sin referir su vigencia a un período de cinco años, con independencia de las modificaciones o actualizaciones que sucesivamente pudieran introducirse en el mismo. Dicha Comisión concluyó que el hecho 
de que el Consejo de Política Fiscal y Financiera estableciera una duración determinada a la generalidad de un modelo de financiación, y no sólo a aquellos recursos para los que se aceptaba su revisión en la LOFCA, no podía entenderse como vinculante, al menos jurídicamente, para los órganos estatales en los que reside la competencia para definir dicho sistema mediante su aprobación por Ley, esto es, las Cortes Generales. Una interpretación distinta supondría, según dicha Comisión, atribuir al Consejo una función y una naturaleza que en cualquier caso no le corresponde como órgano de coordinación, consultivo y de deliberación, que no puede considerarse como órgano decisorio. Además, dicha interpretación ni se infiere del conjunto de normas que regulan los diferentes mecanismos de financiación de las Haciendas autonómicas, ni se ha positivizado en ninguno de los instrumentos normativos que regulan jurídicamente el contenido de los acuerdos. Por tanto, el hecho de que el Consejo de Política Fiscal y Financiera haya utilizado la referencia temporal para proyectar la vigencia de un modelo de financiación completo constituye un compromiso político realizado al margen de las exigencias normativas y que, por esa misma razón, no puede entenderse vinculante para las Cortes Generales.

Acogiendo esa recomendación de la Comisión, el Gobierno propuso para su aprobación en el Consejo de Política Fiscal y Financiera un modelo de financiación no circunscrito a un quinquenio (2002-2006) sino de aplicación y vigencia indefinida. El modelo vigente en la actualidad, que como ya hemos indicado fue finalmente aprobado por el Consejo en su sesión de 27 de julio de 2001, nació con vocación de estabilidad sin fijación de una vigencia temporal determinada. No obstante, esta vocación de perdurabilidad no está reñida, como bien advirtió la Comisión antes citada en su Informe, con la posibilidad de efectuar aquellas reformas parciales que puedan requerir las circunstancias que sobrevengan en el futuro.

En ese sentido, la Secretaría de Estado de Hacienda y Presupuestos ha publicado recientemente un interesante estudio titulado Problemática del sistema de financiación de las comunidades autónomas de régimen común regulado en la ley orgánica 8/1980 y en la ley 21/2001, en el que se analiza fundamentalmente el comportamiento de los distintos recursos del sistema de financiación, con especial atención a los recursos tributarios, entre 1999 y 2004. En dicho Informe se afirma que a pesar de la vocación de permanencia con la que fue aprobado el sistema y de que sólo se dispone de cifras sobre la aplicación plena respecto de tres ejercicios (2002 a 2004), acontecimientos vinculados a las propias características del mismo, al incremento de la población de forma heterogénea entre las Comunidades Autónomas (debido, fundamentalmente, a la inmi- 
gración), así como a factores endógenos y exógenos vinculados a la prestación pública de la sanidad, entre otras razones, han hecho que se plantee el análisis de lo acontecido durante los cinco años de vigencia del sistema (2002 a 2006). El Informe realiza pues un diagnóstico del actual sistema de financiación, diagnóstico que debe servir de base para comenzar los trabajos de revisión del mismo. Entre los aspectos más llamativos de este Informe destaca, en lo que afecta a la Comunidad Autónoma de Andalucía, el crecimiento de la recaudación del Impuesto sobre la Renta de las Personas Físicas con 20 puntos porcentuales por encima de la media. Se trata de un crecimiento que tiene extraordinaria importancia pues se ha producido en el caso de Andalucía con un aumento de la población del 5,2\%. Otras Comunidades Autónomas con importantes crecimientos en la recaudación del Impuesto sobre la Renta de las Personas Físicas, como es el caso de Murcia y Castilla-La Mancha, concretamente de 29 y 26 puntos porcentuales, han tenido aumentos de población del $14 \%$ y $7 \%$, respectivamente. Por tanto, el crecimiento de la recaudación por IRPF en el caso de Andalucía resulta especialmente destacable ya que se ha producido con un aumento menor de la población.

El artículo 177 del nuevo Estatuto de Andalucía, en la línea de lo dispuesto en el artículo 208 del Estatuto de Cataluña, se refiere a la actualización del sistema de financiación, estableciendo que dicha actualización será quinquenal y que se tendrá en cuenta para ello "la evolución del conjunto de recursos públicos disponibles y de las necesidades de gastos de las diferentes Administraciones". No obstante, se añade que dicha actuación deberá efectuarse "sin perjuicio del seguimiento y eventualmente puesta al día de las variables básicas utilizadas para la determinación de los recursos proporcionados por el sistema de financiación". La competencia para aprobar dicha actualización recae sobre la Comisión Mixta de Asuntos Económicos y Fiscales Estado-Comunidad Autónoma.

\section{FUENTES DE FINANCIACIÓN DE LAS COMUNIDADES AUTÓNOMAS}

Una vez que sabemos dónde se encuentra contenida la regulación básica del sistema de financiación y cómo se aprueba dicho sistema es conveniente examinar cuáles son las principales fuentes de financiación de las Comunidades Autónomas. Podemos distinguir para clarificar la situación varios bloques de recursos.

El primer bloque está constituido por los recursos de naturaleza tributaria. De ellos se ocupa el artículo 176 del nuevo Estatuto de Andalucía, con mucho más detalle que el Estatuto anterior. Dentro de este bloque se incluyen en 
primer lugar los impuestos cedidos. Se trata de impuestos cuya regulación es básicamente estatal, pero cuya recaudación se encuentra cedida total o parcialmente a las Comunidades Autónomas. Y decimos que la regulación es básicamente estatal porque las Comunidades Autónomas disponen de competencias normativas que les permiten regular determinados aspectos de estos impuestos. En el epígrafe siguiente estudiaremos detenidamente esta importantísima fuente de financiación y los problemas que existen en la actualidad como consecuencia del ejercicio por las Comunidades Autónomas de esas competencias normativas.

En este primer bloque entrarían también los tributos autonómicos propios (impuestos, tasas o contribuciones especiales) que puedan crear las Comunidades Autónomas. También dedicaremos un epígrafe al estudio del papel que han desempeñado estos recursos en el sistema de financiación como instrumentos de responsabilidad fiscal y el que pueden desempeñar en el futuro, así como a comentar los conflictos a que han dado lugar en muchos casos ante el Tribunal Constitucional.

Y en tercer lugar, el nuevo Estatuto también cita entre los recursos de naturaleza tributaria los recargos sobre tributos estatales. Se trata de recursos a los que se ha dispensado escasa atención tanto en la Constitución como en la LOFCA. En efecto, el artículo 157.1, a) de nuestra Carta Magna simplemente se limita a incluirlos en el listado de medios de financiación con que contarán las Comunidades Autónomas. Por su parte, el artículo 12 LOFCA en la redacción dada a este precepto por la Ley Orgánica 7/2001, de 27 de diciembre, admite los recargos como una fuente de financiación, añadiendo que los podrán establecer las Comunidades Autónomas sobre los tributos del Estado susceptibles de cesión, excepto en el Impuesto sobre las Ventas Minoristas de Determinados Hidrocarburos. Por lo que respecta al Impuesto sobre el Valor Añadido e Impuestos Especiales únicamente podrán establecer recargos cuando tengan competencias normativas en materia de tipos de gravamen. Por último, se dispone que estos recargos no podrán configurarse de forma que puedan suponer una minoración en los ingresos del Estado por dichos impuestos, ni desvirtuar la naturaleza o estructura de los mismos. Hasta la fecha dos Comunidades Autónomas han establecido recargos sobre el Impuesto sobre la Renta de las Personas Físicas (en concreto País Vasco y Madrid, aunque este último no llegó a aplicarse) y varias han creado recargos sobre los tributos sobre juegos de suerte, envite o azar.

Otro grupo importante de recursos de las Comunidades Autónomas está constituido por los instrumentos que tratan de hacer efectivo el principio de 
solidaridad. Como ya ha quedado expuesto, el principio de solidaridad pretende facilitar la consecución de un nivel equivalente en la prestación de servicios, al margen de la mayor o menor capacidad fiscal de cada Comunidad Autónoma. En el sistema actualmente vigente, los principales instrumentos previstos para hacer efectivo dicho principio son:

- Fondo de renta relativa. Tiene por objeto compensar la menor riqueza relativa de la Comunidad Autónoma correspondiente. Para ello se utiliza como variable de reparto el índice ponderado de renta relativo previsto en el artículo 4.A, d) de la Ley 21/2001. Este Fondo se distribuye entre aquellas Comunidades Autónomas cuyo índice de renta relativa es positivo y en proporción a éste

- Fondo para paliar la escasa densidad de población. Dotado con 48,08 millones de euros, tiene por objeto reforzar el principio de solidaridad y se aplica con el fin de paliar la situación en que se encuentran las Comunidades Autónomas que hayan experimentado un proceso de despoblación importante. Este Fondo se distribuye entre aquellas Comunidades Autónomas con una densidad de población inferior a 27 habitantes por kilómetro cuadrado, siempre que, además, su extensión superficial sea inferior a 50.000 kilómetros cuadrados.

- Modulación de crecimiento. Determina que aquellas Comunidades cuya renta por habitante sea inferior al 70 por 100 de la renta por habitante media de las Comunidades Autónomas de régimen común no puedan crecer por debajo del 120 por 100 de la media de crecimiento del conjunto de las Comunidades de régimen común. A su vez, para las que se encuentren situadas entre el 70 y el $75 \%$ de la renta por habitante media, la tasa de crecimiento de su financiación no podrá ser inferior al $30 \%$ de la tasa media de crecimiento del conjunto de Comunidades Autónomas de régimen común. Por último, para las que se hallen entre el $75 \%$ y el $82 \%$ de la renta por habitante media, la tasa de crecimiento de su financiación no podrá ser inferior al $22 \%$ de la tasa media de crecimiento del conjunto de Comunidades Autónomas de régimen común.

- Fondo de desplazados (o de cohesión sanitaria). Mediante este Fondo se trata de garantizar el acceso de todos los ciudadanos a los servicios sanitarios en todo el territorio nacional, independientemente de la Comunidad Autónoma de residencia.

- Respeto del status quo. Determina que ninguna Comunidad Autónoma perciba, para cada bloque competencial, menos recursos de los que le correspondían con el sistema anterior. 
Con el fin de hacer efectivo también el principio de solidaridad y como complemento de los anteriores instrumentos también debemos citar los Fondos de Compensación Interterritorial, regulados en la Ley 22/2001, antes citada. Estos Fondos proceden del antiguo Fondo de Compensación Interterritorial que podía financiar gastos de inversión pero no gastos corrientes. Ahora dicho Fondo se desdobla en dos distintos, el Fondo de Compensación, que se ciñe estrictamente al mandato constitucional y el Fondo Complementario, que puede financiar la puesta en marcha de inversiones hasta un máximo de dos años. Junto a los Fondos también hay que mencionar las asignaciones de nivelación de los servicios públicos fundamentales del artículo 15 de la LOF$\mathrm{CA}$, que son recursos suplementarios que tienen por objeto garantizar una prestación de los servicios de educación y sanidad sin grandes divergencias en los diferentes territorios regionales. La Ley Orgánica 7/2001, de modificación de la LOFCA y la Ley 21/2001 introdujeron importantes novedades en la regulación de estas asignaciones, en el sentido de concretar las situaciones en las que se considera que puede haber una desviación en el nivel mínimo de prestación de los servicios citados de educación y sanidad.

Otra importante fuente de financiación de las Comunidades es el llamado Fondo de Suficiencia, que está previsto como mecanismo de cierre del sistema. Su cálculo se realiza por diferencia, en el año base 1999, entre las necesidades de financiación de cada Comunidad Autónoma y la valoración de los recursos de naturaleza tributaria anteriores. Además el Fondo de Suficiencia es el mecanismo de ajuste del Sistema a los cambios que puedan producirse en las necesidades de financiación de las Comunidades Autónomas (por traspaso de servicios) o en los recursos (por nuevas cesiones de impuestos).

Además de estos recursos, la Ley 21/2001, establece el derecho de las Comunidades Autónomas a la percepción de una garantía para que tengan cubierta una financiación mínima de los servicios de asistencia sanitaria durante los tres primeros años de vigencia del sistema de financiación.

Entre las fuentes de financiación de las Comunidades Autónomas no puede olvidarse citar las transferencias que estos entes territoriales perciben de la Unión Europea, en particular los Fondos estructurales europeos que tienen por finalidad aproximar sus niveles de renta y riqueza. Las cuantiosas transferencias que han venido recibiendo las Comunidades Autónomas por este concepto han procedido fundamentalmente de tras instrumentos: el Fondo Europeo de Desarrollo Regional, el Fondo Social Europeo y el Fondo de Orientación y Garantía Agraria Sección Orientación. El artículo 185 del nuevo Estatuto de Autonomía para Andalucía se refiere a la gestión de todos los fondos 
europeos que tengan como destinatario a la Comunidad Autónoma, atribuyéndola a ésta su gestión, planificación y ejecución, añadiendo que dichos fondos podrán ser modulados con criterios sociales y territoriales, por supuesto siempre dentro del respeto a las normas europeas aplicables.

Antes de concluir esta enumeración de las fuentes de financiación debemos mencionar los ingresos que puedan obtener estos entes territoriales a través del recurso al endeudamiento, para el que se establecen importantes límites en el artículo 14 de la LOFCA. En desarrollo de lo allí dispuesto, el artículo 187 del nuevo Estatuto de Autonomía regula las condiciones en las que la Comunidad Autónoma puede emitir deuda pública, el volumen y características de las emisiones, distinguiendo igual que la LOFCA entre operaciones de crédito por plazo superior o inferior a un año.

Igualmente debemos mencionar los ingresos patrimoniales, a los que se refiere el nuevo Estatuto en su artículo 188 y los derivados de multas o sanciones. Dentro de los ingresos patrimoniales se incluirían los recursos que deriven de la explotación o venta de los bienes que integran su patrimonio, por la realización de actividades empresariales, así como los intereses que perciban por las cuentas bancarias de las que sean titulares.

Con el fin de que pueda verse la importancia que tiene cada uno de estos recursos en el sistema de financiación se incluye al final de este trabajo un cuadro que está tomado de los datos publicados en julio de 2006 por el Ministerio de Economía y Hacienda sobre la liquidación del sistema de financiación en el año 2004, que es el último ejercicio sobre el que se han publicado datos hasta la fecha.

\section{LOS IMPUESTOS CEDIDOS COMO INSTRUMENTOS DE CO- RRESPONSABILIDAD FISCAL: DE LA CESIÓN DE RECAUDA- GIÓN A LA CESIÓN DE COMPETENCIAS NORMATIVAS}

Los impuestos cedidos constituyen en la actualidad la principal fuente de financiación de las Comunidades Autónomas. De acuerdo con la redacción actual del artículo 10 de la LOFCA los tributos cedidos son aquellos establecidos y regulados por el Estado cuyo producto, total o parcialmente, corresponde a las Comunidades Autónomas, que también pueden ejercer, según los casos, competencias normativas y de gestión sobre los mismos. Por tanto, el concepto de impuesto cedido conlleva actualmente tanto la cesión de todo o parte de la recaudación de un determinado impuesto estatal, como la posibilidad de 
ejercer determinadas competencias normativas. Sin embargo, con anterioridad al 1 de enero de 1997 la situación era distinta. En efecto, la primera Ley de cesión de tributos a las Comunidades Autónomas, que fue la Ley 30/1983, estableció un concepto de impuesto cedido en el que no cabía la cesión de competencias normativas. Con buen criterio no se estimó oportuno cederles competencias de ese tipo en relación con los impuestos estatales, ya que los beneficiarios de la cesión eran unos entes territoriales que aún no se habían consolidado como tales.

Dentro de los tributos cedidos el nuevo Estatuto de Andalucía distingue en su artículo 178 dos grandes grupos:

1. Tributos estatales cedidos totalmente.

Aunque no lo haga el Estatuto de Andalucía, dentro de este primer grupo se puede a su vez distinguir entre los tributos cedidos tradicionales y los tributos cedidos a partir de 2002 .

A) Tributos cedidos tradicionales.

Son aquellos cuya recaudación se encuentra cedida desde la primera Ley de cesión, la citada Ley 30/1983. Son los siguientes: Impuesto sobre el Patrimonio, sobre Sucesiones y Donaciones, sobre Transmisiones Patrimoniales y Actos Jurídicos Documentados y los Tributos sobre el Juego. Hasta el 31 de diciembre de 1996 estuvo cedida la totalidad de la recaudación de estos tributos a las Comunidades Autónomas y las competencias para la gestión de los tres últimos tributos, ya que en el caso del Impuesto sobre el Patrimonio la gestión ha sido y sigue siendo compartida con la Agencia Estatal de Administración Tributaria, dada la función de control que cumple el Impuesto sobre el Patrimonio.

En contraste con estas amplias facultades en materia de gestión, las Comunidades Autónomas no dispusieron inicialmente de ninguna facultad normativa sobre estos impuestos. Fue a partir del 1 de enero de 1997 cuando se les cedieron por el Estado competencias normativas que en los tres primeros casos se circunscribían, con diversos condicionantes, al establecimiento de las tarifas, a la fijación de coeficientes multiplicadores a aplicar en atención al patrimonio preexistente y grado de parentesco y a la regulación de las reducciones en la base imponible del Impuesto sobre Sucesiones y Donaciones. En los tributos que gravan las diversas modalidades de juegos, las competencias normativas atribuidas a las Comunidades Autónomas eran más amplias ya que se 
les habían otorgado facultades para actuar sobre las exenciones, base imponible, tipo de gravamen, cuotas fijas, bonificaciones, devengo y diversos aspectos relacionados con la gestión, entendiendo este término en sentido amplio. A pesar de que formalmente siguen siendo tributos de titularidad estatal, la totalidad de aspectos importantes de estas figuras son regulados por las Comunidades Autónomas. A la vista de la regulación actual quizás sería conveniente que los tributos sobre el juego pasen a ser tributos propios.

Con la entrada en vigor el 1 de enero de 2002 del sistema de financiación autonómica vigente en la actualidad se produjo una ampliación de las competencias normativas en relación con estos impuestos cedidos tradicionales.

En relación con el Impuesto sobre el Patrimonio, en el que hasta el 31 de diciembre de 2001 la tarifa debía cumplir los requisitos de tener una estructura con progresividad similar a la del Estado y ser idéntica a la de éste en cuanto a la cuantía del primer tramo de base liquidable y tipo marginal mínimo, la novedad que se introdujo consistió en que la tarifa ya no tendrá condicionante alguno, pudiendo incluso fijarse un único tipo de gravamen. Hasta la fecha, las Comunidades Autónomas han hecho poco uso de su competencia para regular la tarifa de este impuesto pues solo Cantabria ha establecido una tarifa distinta de la regulada por la ley estatal. Ahora bien, sí se han aprobado en este período diferentes cuantías de mínimos exentos, en algunos casos aplicables con carácter general y en otros solo aplicables a contribuyentes minusválidos.

También se ampliaron con la entrada en vigor del nuevo modelo de financiación las competencias normativas en relación con el Impuesto sobre Transmisiones Patrimoniales y Actos Jurídicos Documentados, de manera que las Comunidades Autónomas pueden en la actualidad regular el tipo de gravamen en las transmisiones de bienes muebles e inmuebles, la constitución y cesión de derechos reales que recaigan sobre los mismos, así como en el arrendamiento de bienes muebles e inmuebles. Durante el período 1998-2001 siete Comunidades Autónomas incrementaron el tipo de gravamen de la modalidad de Transmisiones Patrimoniales Onerosas aplicable a las transmisiones de inmuebles, que pasó del $6 \%$ al $7 \%$. El resto de las Comunidades de régimen común adoptaron esta misma medida en el período 2002-2005, por lo que en la actualidad el gravamen de esta modalidad se exige al $7 \%$ en todas las CCAA, con la excepción de Canarias que lo ha elevado al 6,5\%. Por lo que se refiere a la cuota gradual de la modalidad Actos Jurídicos Documentados, en el período 2002-2005 todas las Comunidades Autónomas de régimen común han incrementado el tipo pasando del $0,5 \%$ al $1 \%$, a excepción de Canarias que lo ha fijado en el $0,75 \%$. 
Por lo que respecta al Impuesto sobre Sucesiones con el nuevo modelo de financiación también se ampliaron las competencias normativas ya que desaparecieron los condicionantes que existían para la tarifa, de manera que en la actualidad las Comunidades Autónomas pueden aprobar una tarifa sin tramos con un único tipo de gravamen. Por otra parte, también se les permitió establecer reducciones para las transmisiones inter vivos que respondan a circunstancias de carácter económico o social propias de cada una de ellas. Las Comunidades Autónomas han hecho escaso uso de su competencia para regular la tarifa del impuesto (solo dos de ellas han aprobado una tarifa distinta de la establecida en la norma estatal, pero con pocas diferencias respecto de ésta). En cambio, sí han hecho masivamente uso de sus facultades normativas tanto para la modificación de los requisitos para el disfrute de reducciones en la base imponible establecidos en la normativa estatal como para la creación de reducciones propias, fundamentalmente en el ámbito de la transmisión de empresas familiares, vivienda habitual y explotaciones agrarias. En el epígrafe siguiente nos ocuparemos de los problemas que han surgido como consecuencia del ejercicio de competencias normativas en relación con este tributo con el objetivo de eliminarlo para las transmisiones a favor de hijos o del cónyuge.

B) Otros tributos cedidos totalmente a partir de 2002

Con la entrada en vigor del actual sistema de financiación se cedieron también otros tributos que hasta entonces eran de titularidad estatal. Algunos de ellos se cedieron sólo parcialmente, como ocurrió con el Impuesto sobre la Renta de las Personas Físicas, Impuesto sobre el Valor Añadido y los Impuestos Especiales sobre Hidrocarburos, Labores del Tabaco, Cerveza, Vino y Bebidas Fermentadas, Productos Intermedios y sobre Alcohol y Bebidas Derivadas. De ellos nos ocuparemos en el siguiente apartado. Ahora nos vamos a limitar a comentar los impuestos que se cedieron totalmente.

Dentro de los impuestos cuya recaudación líquida se cedió totalmente a partir de 2002 tenemos en primer lugar al Impuesto sobre la Electricidad. En relación con este tributo no se han cedido competencias normativas a las Comunidades Autónomas.

En segundo término, dentro de este grupo se incluye también el Impuesto Especial sobre Determinados Medios de Transporte. Se encuentra cedido a las Comunidades Autónomas el 100\% de su recaudación líquida, así como facultades normativas en relación con los tipos de gravamen, aunque con determinados límites. En concreto, las Comunidades Autónomas pueden modificar los tipos en un $10 \%$. Este margen para la elevación del tipo ha sido in- 
crementado por la Ley 25/2006, de 17 de julio, por la que se modifica el régimen fiscal de las reorganizaciones empresariales y del sistema portuario y se aprueban medidas tributarias para la financiación sanitaria y para el sector del transporte por carretera, pasando del $10 \%$ al $15 \%$. Hasta el momento ninguna Comunidad ha ejercido competencias en este impuesto.

En tercer lugar, se cedió a las Comunidades un tributo que fue creado por la Ley 21/2001, antes citada. Se trata del llamado Impuesto sobre las Ventas Minoristas de Determinados Hidrocarburos, exigible en todo el territorio español con excepción de Canarias, Ceuta y Melilla. Su tipo de gravamen es la suma de un tipo estatal y otro tipo autonómico, que se concreta en una banda dentro de la que cada Comunidad Autónoma puede fijar el nivel de tributación. Hasta el momento sólo algunas Comunidades Autónomas han hecho uso de sus competencias normativas en este impuesto. Este es el caso de Madrid que aprobó el tramo autonómico en 2002, Asturias, Galicia y Cataluña que lo implantaron en 2004 y Castilla-La Mancha y Valencia que lo han hecho en 2006. La Ley 25/2006, de 17 de julio, por la que se modifica el régimen fiscal de las reorganizaciones empresariales y del sistema portuario y se aprueban medidas tributarias para la financiación sanitaria y para el sector del transporte por carretera, ha ampliado la banda dentro de la cual las Comunidades Autónomas pueden fijar el tramo autonómico del impuesto. Su recaudación en la parte derivada del tipo estatal quedará afectada a la cobertura de gastos de naturaleza sanitaria, mientras que para la parte que proceda de los tipos de gravamen autonómicos la Ley que lo creó dispone podrá dedicarse a financiar actuaciones medioambientales.

\section{Tributos cedidos parcialmente o compartidos}

La nómina de tributos cedidos se ha ido incrementando con ocasión de las sucesivas reformas del sistema de financiación autonómica en el marco del proceso de descentralización de ingresos desde la Hacienda estatal hacia las Haciendas autonómicas. Este proceso ha ido acompañado de una reducción simultánea de las transferencias que las Comunidades Autónomas venían percibiendo en concepto de su participación en ingresos del Estado. Esta descentralización de ingresos nos ha conducido a que los principales impuestos del sistema tributario español sean tributos cedidos parcialmente o "tributos compartidos" entre el Estado y las Comunidades Autónomas.

En el actual sistema de financiación se encuentran cedidos parcialmente a las Comunidades Autónomas el Impuesto sobre la Renta de las Personas Físicas, el Impuesto sobre el Valor Añadido y los Impuestos Especiales sobre Hi- 
drocarburos, Labores del Tabaco, Cerveza, Vino y Bebidas Fermentadas, Productos Intermedios y sobre Alcohol y Bebidas Derivadas. Tan sólo quedan en manos del Estado, puesto que no se han cedido, los tributos que gravan el tráfico exterior, el Impuesto sobre Sociedades, el Impuesto sobre la Renta de No Residentes y el Impuesto sobre Primas de Seguros.

El Impuesto sobre la Renta de las Personas Físicas se cedió parcialmente a las Comunidades Autónomas a partir del 1 de enero de 1997. Esta cesión tuvo su origen en el Acuerdo de investidura y gobernabilidad que firmaron, tras las elecciones generales de marzo de 1996, el Partido Popular y Convergencia y Unión. Esta cesión parcial se instrumentó en dos fases. En la primera se cedió a las Comunidades Autónomas que aceptaron el modelo de financiación el 15\% de la recaudación del Impuesto sobre la Renta de las Personas Físicas a través del abatimiento de la tarifa estatal al 85\% de los tipos de gravamen. En la segunda fase, que se iniciaría cuando se completase el traspaso de competencias en materia de educación no universitaria, se abatiría otro $15 \%$ la tarifa estatal para así alcanzar un porcentaje de cesión del 30\%. Con la aprobación en 2001 del modelo vigente en la actualidad este porcentaje se elevó hasta situarlo en el 33\% de la recaudación del impuesto.

Las Comunidades Autónomas disponen desde 1997 de importantes competencias normativas en relación con este tributo. Hasta el momento, sólo una Comunidad Autónoma concretamente Madrid ha hecho uso de sus facultades para reducir la tarifa autonómica del impuesto con efectos a partir del 1 de enero 2007. En el siguiente apartado comentaremos esta decisión de la Comunidad madrileña que también ha abierto una guerra entre las Comunidades Autónomas. Donde sí han coincidido todas las Comunidades Autónomas es en hacer uso de sus competencias para aprobar deducciones propias relacionadas con el nacimiento o adopción de hijos, por cuidado de ascendientes y descendientes, exigiéndose para su aplicación diversos requisitos, así como en relación con la adquisición de vivienda o el alquiler. Algunas aplican estas deducciones de forma general y otras limitan su aplicación a determinados colectivos, como jóvenes o minusválidos, o a determinados tipos de vivienda, como vivienda protegida o vivienda situada en el ámbito rural.

Junto al Impuesto sobre la Renta de las Personas Físicas también se encuentra cedido parcialmente a las Comunidades Autónomas desde el 1 de enero de 2002 el 35\% de la recaudación líquida por Impuesto sobre el Valor Añadido, así como el $40 \%$ de la recaudación líquida por Impuesto sobre la Cerveza, sobre el Vino y Bebidas Fermentadas, sobre Productos Intermedios, sobre el Alcohol y Bebidas Derivadas, sobre Hidrocarburos y sobre las Labores 
del Tabaco En relación con estos tributos no se han cedido competencias normativas porque al tratarse de impuestos armonizados hay que respetar las disposiciones contenidas en la normativa comunitaria que impide tal posibilidad. La incorporación de estas figuras a la nómina de tributos cedidos se debió a la inclusión de la sanidad entre los servicios que se financiarían mediante el sistema de financiación. Hasta finales de 2001 la sanidad estaba fuera del sistema de financiación y se regía por un sistema especial. La incorporación de esta importante competencia al sistema hizo necesario ceder parte o la totalidad de la recaudación de las principales figuras del sistema tributario.

El artículo 178 del nuevo Estatuto contiene una previsión importante para el caso de que sea necesaria su modificación en el sentido de incluir algún nuevo tributo en la nómina de impuestos cedidos o de eliminar alguno de ellos. Se trata de su apartado 2 que dispone que su contenido se podrá modificar mediante acuerdo del Estado con la Comunidad Autónoma, que será tramitado como proyecto de ley, sin que ello se considere una modificación del Estatuto. Además se recuerda en su apartado 3 que el alcance y condiciones de la cesión serán fijados en todo caso por la Comisión Mixta "mencionada en el artículo 181". En este punto advertimos un descuido que puede deberse a los cambios que ha sufrido el proyecto de reforma durante la tramitación parlamentaria porque dicho artículo 181 se refiere a la organización de la Administración de la Comunidad Autónoma en materia tributaria.

CUADRO RESUMEN DE LOS TRIBUTOS CEDIDOS POR EL ESTADO A LAS COMUNIDADES AUTÓNOMAS

\begin{tabular}{|l|l|l|l|}
\hline IMPUESTO & RENDIMIENTO & NORMATIVA & GESTIÓN \\
\hline \multicolumn{3}{|l|}{ TRIBUTOS TOTALMENTE CEDIDOS TRADICIONALES } \\
\hline I.Patrimonio & $\begin{array}{l}\text { Comunidades } \\
\text { Autónomas }\end{array}$ & Compartida & $\begin{array}{l}\text { CCAA } \\
\text { compartida } \\
\text { con la AEAT }\end{array}$ \\
\hline ITPAJD & $\begin{array}{l}\text { Comunidades } \\
\text { Autónomas }\end{array}$ & Compartida & $\begin{array}{l}\text { Comunidades } \\
\text { Autónomas }\end{array}$ \\
\hline $\begin{array}{l}\text { I.Sucesiones y } \\
\text { Donaciones }\end{array}$ & $\begin{array}{l}\text { Comunidades } \\
\text { Autónomas }\end{array}$ & Compartida & $\begin{array}{l}\text { Comunidades } \\
\text { Autónomas }\end{array}$ \\
\hline $\begin{array}{l}\text { Tributos sobre } \\
\text { el juego }\end{array}$ & $\begin{array}{l}\text { Comunidades } \\
\text { Autónomas }\end{array}$ & Compartida & $\begin{array}{l}\text { Comunidades } \\
\text { Autónomas }\end{array}$ \\
\hline
\end{tabular}




\begin{tabular}{|l|l|l|l|}
\hline \multicolumn{4}{|l|}{ TRIBUTOS TOTALMENTE CEDIDOS A PARTIR DE 2002} \\
\hline I. Electricidad & $\begin{array}{l}\text { Comunidades } \\
\text { Autónomas }\end{array}$ & Estado & AEAT \\
\hline $\begin{array}{l}\text { I.Especial Medios } \\
\text { Transporte }\end{array}$ & $\begin{array}{l}\text { Comunidades } \\
\text { Autónomas }\end{array}$ & Compartida & $\begin{array}{l}\text { Comunidades } \\
\text { Autónomas }\end{array}$ \\
\hline $\begin{array}{l}\text { I.Ventas Minoristas } \\
\text { Hidrocarburos }\end{array}$ & $\begin{array}{l}\text { Comunidades } \\
\text { Autónomas }\end{array}$ & Compartida & $\begin{array}{l}\text { Comunidades } \\
\text { Autónomas }\end{array}$ \\
\hline TRIBUTOS CEDIDOS PARCIALMENTE O COMPARTIDOS \\
\hline IRPF & $\begin{array}{l}\text { Compartido } \\
(33 \%)\end{array}$ & Compartido & AEAT \\
\hline IVA & $\begin{array}{l}\text { Compartido } \\
(35 \%)\end{array}$ & Estado & AEAT \\
\hline $\begin{array}{l}\text { I.Especiales } \\
\text { (Cerveza, Vino, } \\
\text { Alcohol, } \\
\text { Hidrocarburos y } \\
\text { Tabaco })\end{array}$ & $\begin{array}{l}\text { Compartido } \\
(40 \%)\end{array}$ & Estado & AEAT \\
\hline TRIBUTOS NO CEDIDOS & Estado & AEAT \\
\hline $\begin{array}{l}\text { I. Tráfico exterior } \\
\text { Estado/Unión } \\
\text { Europea }\end{array}$ & $\begin{array}{l}\text { Estado/Unión } \\
\text { Europea }\end{array}$ & AEAT \\
\hline $\begin{array}{l}\text { I.Sociedades } \\
\text { Eestado }\end{array}$ & Estado & AEAT \\
\hline I. Primas Seguros & Estado & Estado & AEAT \\
\hline
\end{tabular}

5. PROBLEMAS DE COMPETENCIA FISCAL ENTRE COMUNIDADES AUTÓNOMAS EN RELACIÓN CON EL IMPUESTO SOBRE SUCESIONES Y DONACIONES

Como avanzamos en el epígrafe anterior, en relación con el Impuesto sobre Sucesiones y Donaciones se ha generado una interesante problemática ya que a través del ejercicio por las Comunidades Autónomas de las competen- 
cias normativas que se les reconocen en relación con este tributo se ha abierto una "guerra fiscal" entre ellas. Nos referimos a la tendencia generalizada que se advierte en los últimos años en las Comunidades de régimen común a la práctica eliminación del gravamen que recae sobre las transmisiones a favor de los hijos menores de 21 años, medida que algunas Comunidades van extendiendo, progresivamente, también a las transmisiones a favor del cónyuge y descendientes de cualquier edad. A pesar de ser un impuesto de titularidad estatal, porque aunque se ceda la recaudación del tributo y competencias normativas el titular del tributo sigue siendo el Estado y por tanto sólo el Estado lo puede suprimir, las Comunidades Autónomas a través de diversas técnicas como el establecimiento de reducciones en la base imponible, deducciones o bonificaciones en la cuota o aprobación de coeficientes multiplicadores inferiores a la unidad, prácticamente han suprimido este impuesto.

Prescindiendo de las Comunidades forales, en la actualidad aproximadamente un 40 por 100 de los contribuyentes españoles (alrededor de 17 millones de españoles) está prácticamente exento, o lo estará a lo largo de este año, de tributar por el Impuesto sobre Sucesiones. Además de los casos ya conocidos del País Vasco y Navarra, no tributarán prácticamente por este tributo los contribuyentes que residan en las Comunidades de Baleares, Cantabria, Castilla y León, Comunidad Valenciana, La Rioja, Madrid y Murcia. En estas Comunidades Autónomas se aplica una bonificación en la cuota para las transmisiones mortis causa a favor de los hijos y otros parientes cercanos que implica la práctica exención del tributo. Aparte de esta bonificación en la mayoría de Comunidades Autónomas (aparte de las ya citadas habría también que mencionar a Andalucía, Aragón, Asturias, Canarias y Castilla-La Mancha) se aplican reducciones que afectan a la transmisión mortis causa o inter vivos de empresas familiares, vivienda habitual o explotaciones agrarias.

En relación con el Impuesto sobre Donaciones también algunas Comunidades Autónomas se han lanzado a aprobar importantes reducciones que prácticamente han conducido a la eliminación del gravamen. La primera en hacerlo ha sido la Comunidad de Madrid que a través de su Ley 7/2005, de 23 de diciembre, aprobó para los contribuyentes residentes en su territorio una bonificación del 99 por 100 en el Impuesto sobre Donaciones. El 1 por 100 restante lo mantiene a efectos de control fiscal. Esta medida afecta a las donaciones percibidas por los sujetos incluidos en los grupos I y II de parentesco de los previstos en el artículo 20.2.a) de la Ley 29/1987, de 18 de diciembre, del Impuesto sobre Sucesiones y Donaciones, es decir, descendientes, adoptados, cónyuges, ascendientes y adoptantes del donante. A estos efectos, se asimilarán a cónyuges los miembros de uniones de hecho que cumplan los re- 
quisitos establecidos en la Ley 11/2001, de 19 de diciembre, de Uniones de Hecho de la Comunidad de Madrid. El problema es, como ahora explicaremos, que esta medida también está beneficiando a los residentes en otras Comunidades Autónomas que compren un inmueble en Madrid y posteriormente lo donen a sus hijos.

Desde que entró en vigor esta medida el 1 de enero de 2006 se ha producido un incremento considerable en el número de donaciones en Madrid. En efecto, desde ese momento los asesores fiscales están recomendando a sus clientes titulares de grandes patrimonios que si desean realizar donaciones en vida a sus hijos sin apenas coste fiscal alguno pueden hacerlo donándoles un inmueble situado en la Comunidad de Madrid. Como el punto de conexión en el caso de donación de inmuebles es el lugar donde radique dicho inmueble, la operación tributaría por el Impuesto sobre Donaciones en Madrid, es decir, beneficiándose de la reducción. Por tanto, ni donante ni donatario tendrían que tener fijada su residencia en Madrid para tributar en esta Comunidad Autónoma por dichas donaciones, a diferencia de lo que ocurre con las herencias, porque en éstas se aplica la normativa de la región donde vivía la persona fallecida.

Para el donatario la operación desde el punto de vista fiscal es tremendamente atractiva por varios motivos. En primer lugar porque al recibir el piso situado en la Comunidad de Madrid por donación prácticamente no tributaría por ese impuesto a dicha Comunidad. Y en segundo lugar, porque si lo que quiere es dinero posteriormente podría vender el inmueble donado inmediatamente o cuando quisiera y sólo tributaría por la ganancia patrimonial que obtuviera, si es que hubiera ganancia patrimonial, al tipo del 18 por 100 que es el gravamen que soporta el ahorro en el Impuesto sobre la Renta de las Personas Físicas desde el 1 de enero de 2007. Por poner un ejemplo, nada impide que un padre residente en Andalucía que quiera realizar una donación sin apenas soportar coste fiscal a su hijo, residente en Valencia, le compre un piso a dicho hijo en Madrid.

Por poner un ejemplo para que se vea la diferencia pensemos por ejemplo en un padre viudo y residente en Madrid que dona a su único hijo que vive en Toledo un inmueble de su propiedad situado en el Paseo de Gracia de Barcelona. El valor de dicho piso a efectos del Impuesto sobre Sucesiones y Donaciones es de 300.000 euros. Supongamos que el hijo tiene un patrimonio anterior de 380.000 euros. En este caso la cuota del impuesto que tendría que pagar como consecuencia de esta donación se elevaría a algo más de 53.000 euros. 
En cambio, pensemos en un padre viudo residente en Barcelona que dona a su único hijo que reside también en Toledo un piso situado en el Paseo de la Castellana de Madrid, valorado también en 300.000 euros, siendo también 380.000 euros el patrimonio preexistente del hijo. En este caso la cuota sería algo más de 500 euros. Evidentemente la operación tendría algún coste fiscal porque habría que pagar el 1 por 100 de Impuesto sobre Actos Jurídicos Documentados, pero en todo caso estos costes serían inferiores a los que se generarían si se tuviera que tributar por la donación en otra Comunidad Autónoma que no fuera Madrid. Para que ese coste fuera mínimo la compra y la donación tendrían que ser simultáneas porque de otra forma el progenitor podría también tener que rendir cuentas a Hacienda por el Impuesto sobre la Renta por la plusvalía generada con ocasión de la donación del inmueble.

Cuando la donación fuera en metálico o en cualquiera de los bienes o derechos contemplados en el artículo 12 de la Ley 19/1991, de 6 de junio, del Impuesto sobre el Patrimonio, la bonificación del 99 por 100 solo resultará aplicable cuando el origen de los fondos donados esté debidamente justificado, siempre que, además, se haya manifestado en el propio documento público en que se formalice la transmisión el origen de dichos fondos.

¿Qué ventajas obtiene la Comunidad de Madrid con esta medida? En principio cabría pensar que el establecimiento de una reducción del 99 por 100 para las donaciones de padres e hijos le supone una pérdida de recaudación importante. Efectivamente, hay pérdida de recaudación en el Impuesto sobre Sucesiones y Donaciones. Pero se trata de un tributo que no es desde luego el más importante en términos recaudatorios para ninguna Comunidad. Esa pérdida de recaudación que desde luego ha sido real se ha visto compensada sobradamente con el incremento de transmisiones de inmuebles que se han producido en la Comunidad de Madrid por parte de los beneficiarios de las donaciones de inmuebles. Y estas transmisiones están sujetas a otro tributo también cedido a las Comunidades Autónomas como es la modalidad Transmisiones Patrimoniales Onerosas del Impuesto sobre Transmisiones Patrimoniales y Actos Jurídicos Documentados. Por tanto, estos tributos irían a parar a las arcas de la Comunidad de Madrid. Por tanto, para la Comunidad de Madrid ese incremento en el número de transmisiones aparte de que ha generado un incremento importante en la actividad económica de la Comunidad también le ha supuesto un incremento en la recaudación por Impuesto sobre Transmisiones que ha compensado con creces lo que se ha dejado de recaudar en concepto de Impuesto sobre Sucesiones y Donaciones. 
A la vista de lo anterior, cabría preguntarse si tiene sentido mantener el Impuesto sobre Sucesiones y Donaciones. Existen argumentos a favor y en contra de este tributo, pero se trata de una cuestión ajena a este trabajo. Únicamente nos limitamos a dejar indicado que tal y como ha quedado configurado el tributo con la introducción de tantas reducciones por parte del Estado y, sobre todo, por parte de las Comunidades Autónomas se ha convertido en un impuesto tremendamente injusto. ¿Qué sentido tiene que un contribuyente que herede las participaciones de una empresa familiar valorada en varios millones de euros prácticamente se encuentre exento del tributo y, en cambio, un contribuyente que herede dinero en una cuenta corriente sí tenga que soportar un tributo, que por cierto es fuertemente progresivo?

\section{EL PAPEL DE LOS IMPUESTOS PROPIOS EN EL SISTEMA DE FINANCIACIÓN. LA HABILITACIÓN DE ESPACIOS FISCALES PROPIOS PARA LAS COMUNIDADES AUTÓNOMAS}

La Constitución española atribuyó poder tributario a las Comunidades Autónomas para que pudiesen establecer sus propios tributos y gozar así de autonomía financiera, no sólo en la vertiente del gasto sino también en la del ingreso. Hasta la fecha el tributo más utilizado ha sido sin duda alguna la tasa. Aparte de las tasas autonómicas que están vinculadas a competencias y servicios que se han transferido a las Comunidades Autónomas, éstas han creado también otras muchas tasas vinculadas a otros servicios.

Pero las Comunidades Autónomas han sido también muy activas a la hora de establecer impuestos propios. Como bien se indica en el Informe recientemente publicado por el Ministerio de Economía y Hacienda que lleva por título Problemática del sistema de financiación de las Comunidades Autónomas de régimen común regulado en la Ley Orgánica 8/1980 y en la Ley 21/2001, antes citado, las Comunidades Autónomas han creado hasta el momento cincuenta impuestos propios. De estos cincuenta, han sido recurridos ante el Tribunal Constitucional argumentando la vulneración de algún precepto contenido en el llamado bloque de la constitucionalidad hasta un total de diecisiete, lo que denota un grado de conflictividad importante.

Los bloques fundamentales son los impuestos sobre el agua (catorce) y los impuestos sobre el bingo (nueve), categorías que han sido pacíficas desde el punto de vista constitucional, circunscribiéndose la conflictividad a los impuestos restantes, que se pueden agrupar en: 
- Impuestos sobre emisiones contaminantes a la atmósfera (cinco, entre ellas Andalucía)

- Impuestos sobre instalaciones o actividades que inciden en el medio ambiente

(cuatro)

- Impuestos sobre residuos (seis, entre ellas Andalucía)

- Impuestos sobre grandes superficies comerciales (cuatro)

- Impuestos sobre propiedad infrautilizada (tres, entre ellas Andalucía)

- Otros, como el impuesto sobre depósitos en entidades de crédito, sobre productos derivados del petróleo, sobre aprovechamientos cinegéticos y el gravamen de protección civil.

Las Comunidades Autónomas que más impuestos propios han creado y tienen vigentes han sido Andalucía (seis), Madrid (cinco) y Murcia (cinco). Les siguen Aragón, Asturias, Extremadura y Cataluña, con cuatro impuestos cada una, Castilla-La Mancha, Galicia e Islas Baleares con tres cada una. Las que menos impuestos propios han creado han sido Canarias, Cantabria, La Rioja y Comunidad Valenciana, con un solo impuesto cada una. Finalmente, solo la Comunidad de Castilla y León carece en la actualidad de impuestos propios.

El nuevo Estatuto de Autonomía para Andalucía establece en su artículo 175.2, d) que nuestra Comunidad "dispondrá de un espacio fiscal propio". ¿Cómo debe interpretarse esta expresión? ¿Se trata de una mera declaración de intenciones o más bien estamos ante un mandato al legislador para que la Comunidad Autónoma cuente con un mayor espacio que el que dispone hasta ahora para poder establecer impuestos propios? Nos inclinamos por esta segunda interpretación, aunque hay que tener en cuenta que actualmente existen importantes límites constitucionales al ejercicio del poder tributario autonómico que han sido establecidos por el Estado.

Como consecuencia de los límites que ahora expondremos las Comunidades Autónomas deben hacer un importante esfuerzo de imaginación fiscal para encontrar hechos o materias imponibles que no hayan sido ya gravados por el Estado. Resulta, pues, extraordinariamente difícil inventar nuevos impuestos. Veamos cuáles son los principales límites.

El primero de estos límites está previsto en el artículo 6.2 LOFCA. En él se dispone que las Comunidades Autónomas "no pueden establecer tributos sobre hechos imponibles gravados por el Estado". El alcance de esta prohibi- 
ción ha sido precisado por el Tribunal Constitucional con ocasión de un recurso de inconstitucionalidad planteado contra los preceptos de la Ley andaluza 8/1984, de 3 de julio, de Reforma Agraria que regulan el llamado Impuesto sobre Tierras Infrautilizadas, un tributo que nunca ha sido aplicado. En aquella ocasión el Tribunal afirmó que el artículo 6.2 LOFCA "no tiene por objeto impedir a las Comunidades Autónomas que establezcan tributos propios sobre objetos materiales o fuentes impositivas ya gravadas por el Estado, porque, habida cuenta de que la realidad económica en sus diferentes manifestaciones está toda ella virtualmente cubierta por tributos estatales, ello conduciría (...) a negar en la práctica la posibilidad de que se creen, al menos, por el momento, nuevos impuestos autonómicos" (STC 37/1987), añadiendo que nada impide que "en relación con una misma materia impositiva, el legislador pueda seleccionar distintas circunstancias que den lugar a otros tantos hechos imponibles, determinantes a su vez de figuras tributarias diferentes". En realidad, lo que quiere prohibir esa norma, según concluye el Tribunal, es "la duplicidad de hechos imponibles, estrictamente" [STC 37/1987, FJ 14 y en términos similares STC 186/1993, FJ 4 c) ]. Esta acertada jurisprudencia del Tribunal Constitucional ha servido para no cerrar el hecho que la Constitución había abierto al ejercicio del poder tributario de las Comunidades Autónomas.

La mayoría de impuestos creados por las Comunidades Autónomas hasta la fecha no plantean ningún problema de compatibilidad respecto de esta norma porque cuando se crearon no existía ningún impuesto estatal sobre los hechos imponibles gravados por dichos impuestos. Ello se debe a que una parte muy importante de ellos recae sobre el medio ambiente o el juego, que son materias sobre las que el Estado central había mostrado un tradicional abandono. En ambos casos se trata de sectores cuyo gravamen no generaba problemas de rechazo social. En efecto, socialmente no está mal visto establecer tributos sobre el medio ambiente o sobre el juego. En el primer caso existe además un principio recogido en el Tratado de la Unión Europea que es el de quien contamina paga, que pretende hacer recaer los costes de la reparación de los daños ambientales sobre sus causantes. Y en cuanto al juego, tampoco hay especiales problemas porque el jugador demuestra una capacidad económica que fundamenta el gravamen de esta actividad.

No obstante, en alguna ocasión se ha planteado ante los Tribunales de justicia la posible vulneración del artículo 6.2 LOFCA. Esto ha ocurrido por ejemplo en el caso del Impuesto gallego sobre la contaminación atmosférica. Galicia fue la primera Comunidad que estableció un tributo sobre emisiones contaminantes a la atmósfera. En este caso se denunciaba un solapamiento 
entre dicha figura y el Impuesto estatal sobre Electricidad. En este punto compartimos los razonamientos expresados por el Tribunal Superior de Justicia de Galicia en su Sentencia de 17 de noviembre de 2005. Como señala con claridad el Tribunal no existe doble imposición porque los hechos imponibles de ambas figuras son diferentes. Así, el hecho imponible del impuesto gallego está constituido por la emisión de sustancias contaminantes, es decir, por el hecho de contaminar. En cambio, en el Impuesto sobre Electricidad, el hecho imponible es la fabricación o producción, importación y adquisiciones intracomunitarias de energía eléctrica. La diferencia por tanto está en que mientras que en el tributo gallego lo que se grava es el foco de contaminación, en el impuesto estatal lo que se grava es un producto final que es la electricidad.

La duda en cambio sí podría plantearse en el supuesto de que el Estado crease ahora un impuesto que gravase el mismo hecho imponible que el tributo gallego. En ese caso sería de aplicación lo previsto en el artículo 6.4 LOFCA. Este precepto que hasta la fecha no ha sido aún aplicado dispone que cuando el Estado, en el ejercicio de su potestad tributaria originaria establezca tributos sobre hechos imponibles gravados por las Comunidades Autónomas, que supongan a éstas una disminución de ingresos, instrumentará las medidas de compensación o coordinación adecuadas en favor de las mismas.

El segundo límite a la creación de impuestos autonómicos al que queremos referirnos está previsto en el apartado 3 del artículo 6 de la LOFCA. Conforme a esta norma, las Comunidades Autónomas sólo podrán establecer tributos sobre materias ya gravadas por las Corporaciones Locales "en los supuestos en que dicha legislación lo prevea y en los términos que la misma contemple". Además, en caso de hacerlo, hay que tener en cuenta que de conformidad con lo previsto en ese precepto "deberán establecerse las medidas de compensación o coordinación adecuadas a favor de aquellas Corporaciones, de modo que los ingresos de tales Corporaciones Locales no se vean mermados ni reducidos tampoco en sus posibilidades de crecimiento futuro".

Por el momento la legislación de régimen local, a través de la disposición adicional quinta de la Ley 39/1988, de Haciendas Locales, ha previsto sólo dos supuestos en los que será aplicable dicha previsión. Se trata de las materias imponibles gravadas por el Impuesto sobre Vehículos de Tracción Mecánica y el Impuesto Municipal sobre Gastos Suntuarios en su modalidad de aprovechamientos de caza y pesca. El principal problema que a nuestro juicio plantea este artículo 6.3 LOFCA es el de clarificar si el legislador con la expresión "materias" quiso referirse al concepto de hecho imponible o al de materia imponible. El Tribunal Constitucional se ha pronunciado sobre esta cuestión en su 
Sentencia 289/2000, de 30 de noviembre, con ocasión de un recurso de inconstitucionalidad planteado contra el Impuesto sobre instalaciones que inciden en el medio ambiente creado por Baleares. El Tribunal declara la inconstitucionalidad de este tributo, por entender que se configura como un impuesto sobre el patrimonio inmobiliario "que incide en la misma materia imponible que la del Impuesto municipal sobre Bienes Inmuebles, incurriendo por ello en la prohibición prevista en el apartado $3^{\circ}$ del artículo 6 LOFCA". Esta Sentencia del Tribunal Constitucional nos parece de extraordinario interés porque fue la primera dictada hasta la fecha por este Tribunal en la que se hizo referencia a los principios o directrices que deben respetar las Comunidades Autónomas a la hora de establecer tributos ambientales.

Quizás, lo verdaderamente interesante de esta Sentencia no es tanto la propia declaración de inconstitucionalidad del tributo balear como el esfuerzo que realiza el Tribunal Constitucional para tratar de poner un poco de orden en el complejo y disperso campo de la fiscalidad ambiental. El máximo intérprete de nuestra Constitución llega a la conclusión de que por mucho que la exposición de motivos exteriorice esa pretendida finalidad protectora del medio ambiente, estamos "en presencia de un tributo que no grava directamente la actividad contaminante, sino la titularidad de unas determinadas instalaciones y (...) el hecho de que el valor de esas instalaciones se calcule mediante la capitalización de los ingresos no trasmuta lo que es impuesto sobre unos elementos patrimoniales en un impuesto sobre actividades contaminantes". A juicio del Tribunal, este tributo "bajo la aparente finalidad protectora del medio ambiente, no arbitra instrumento alguno que se dirija a la consecución de ese fin, con lo que, a la postre, no grava la capacidad económica pretendidamente sometida a imposición, como una forma de contribuir al sostenimiento del gasto público que genera la indebida, o incluso debida, utilización del medio ambiente (manifestación concreta del principio de quien contamina paga)". Si lo efectivamente gravado fuese la actividad contaminante, prosigue el Tribunal, "se habrían sometido a imposición todas aquellas instalaciones, cualquiera que fuese la clase de actividad a la que se hallasen afectas, que de alguna manera pudiesen atentar contra ese medio ambiente, buscando un efecto disuasorio o estimulante de la realización de conductas dañinas o protectoras del entorno ecológico en el que se desenvuelve la actividad". Por todo lo anterior, el Tribunal concluye que el tributo balear es inconstitucional por configurarse como un "impuesto sobre el patrimonio inmobiliario" y gravar la misma materia imponible que el Impuesto sobre Bienes Inmuebles. Por tanto, si este impuesto balear hubiese gravado realmente la actividad contaminante ninguna objeción cabría hacerle desde la perspectiva del artículo 6.3 LOFCA en relación con el Impuesto municipal sobre Bienes Inmuebles, ya 
que según el Tribunal "ambos impuestos gravarían fuentes de riqueza distintas y, en consecuencia, afectarían a materias imponibles dispares”.

En relación con el contenido del artículo 6.3 LOFCA el Tribunal afirma que se trata de un límite que "reconduce la prohibición de duplicidad impositiva a la materia imponible efectivamente gravada por el tributo en cuestión, con independencia del modo en que se articule por el legislador el hecho imponible" (STC 289/2000, FJ 4). El Tribunal Constitucional considera, por tanto, que cuando el legislador utilizó en el artículo 6.3 LOFCA la expresión "materias" quiso referirse al concepto materia imponible y no al hecho imponible. A nuestro juicio la interpretación que realiza el Tribunal del alcance y contenido de dicho precepto resulta discutible. Con el debido respeto que nos merece el Alto Tribunal, creemos que en su razonamiento no ha tenido en cuenta una premisa básica. Los diversos apartados del artículo 6 LOFCA deben ser interpretados de forma coordinada, porque en ese precepto se establecen varias reglas de conflicto en la distribución del poder tributario entre los diversos niveles de gobierno. Por ello, no parece demasiado lógico que el legislador quisiera aludir en el apartado 3 a la materia imponible, cuando antes en el apartado 2 había empleado la expresión hecho imponible. pensamos que el legislador usó la palabra "materias" por una simple fórmula de estilo, para evitar la repetición en tres ocasiones en un mismo precepto de la expresión hecho imponible. Además, en la redacción original del Proyecto de Ley Orgánica de Financiación de las Comunidades Autónomas se utilizaba en el precepto que estamos analizando la expresión "hechos imponibles". Más tarde, en el borrador del Preinforme de la Ponencia se podía leer que las Comunidades Autónomas "podrán establecer tributos sobre las materias (hechos imponibles)...". Aunque posteriormente se suprimiera el paréntesis, estaba clara desde el principio cuál era la intención del legislador.

Pero prescindiendo ahora del problema del alcance exacto que debe darse a la expresión "materias", lo que no cabe discutir es que si se quiere dejar un hueco a las Comunidades Autónomas para que puedan desplegar su poder tributario y ejercer su responsabilidad fiscal ante los ciudadanos, no tiene demasiado sentido concluir que el apartado 3 les prohíbe la posibilidad de inventar tributos sobre materias imponibles ya gravadas por las Corporaciones Locales. Si ello es así, el poder tributario de las Comunidades Autónomas sería un poder muy limitado y me atrevería a decir casi vacío de contenido real. Por todo lo anterior, entendemos que sería conveniente que el legislador tomase en consideración la posibilidad de modificar la redacción del apartado 3 del artículo 6 LOFCA a fin de sustituir la expresión "materias" por "hecho imponible". 
Otro importante grupo de límites al ejercicio del poder tributario autonómico está constituido por los principios previstos en los artículos 157.2 y 139.2 de la Constitución. Todos ellos se refieren a la posible actuación de las Comunidades Autónomas en ejercicio de dicho poder en el ámbito territorial que le es propio.

El artículo 157.2 de la Constitución dice lo siguiente:

"Las Comunidades Autónomas no podrán en ningún caso adoptar medidas tributarias sobre bienes situados fuera de su territorio o que supongan obstáculo para la libre circulación de mercancías o servicios".

En esta norma se formulan dos principios diferentes. Conforme al primero de ellos, que usualmente suele denominarse por la doctrina como principio de territorialidad o con la sugerente expresión de ausencia de carga fiscal extraterritorial se prohíbe a las Comunidades Autónomas gravar bienes situados en el territorio de otra Comunidad. El segundo es el denominado principio de neutralidad, conforme al cual estos entes territoriales no pueden crear obstáculos fiscales a la libre circulación de mercancías o servicios. Este segundo principio prohíbe, por tanto, la creación de cualquier tipo de barrera fiscal o aduanera como por ejemplo la introducción de un gravamen sobre cualquier bien o servicio que pretenda entrar o salir del mercado interior de una Comunidad Autónoma.

El segundo precepto citado se refiere a esta misma cuestión pero regulándola con mayor amplitud. El artículo 139.2 de la Constitución, en el que se consagra implícitamente el principio de unidad de mercado ordena lo siguiente:

"Ninguna autoridad podrá adoptar medidas que directa o indirectamente obstaculicen la libertad de circulación y establecimiento de las personas y la libre circulación de bienes en todo el territorio español".

Esta norma contiene también dos prohibiciones. La primera de ellas afecta a las personas, a las que no se hace referencia en el artículo 157.2, y consiste en que las Comunidades Autónomas no pueden adoptar ningún tipo de medida (no sólo tributaria sino de cualquier otra índole) que pueda ser considerada como un obstáculo para las decisiones que puedan adoptar las personas sobre el establecimiento en uno u otro territorio. La segunda prohibición se refiere a los bienes y es también más general que la contenida en el artículo 157.2. En concreto lo que se prohíbe a las Comunidades Autónomas en el artículo 139.2 es la aprobación de medidas de cualquier tipo que puedan limitar u obstaculizar la libre circulación de bienes en España. 


\section{OTRAS NOVEDADES DEL ESTATUTO ANDALUZ EN MATERIA DE FINANCIACIÓN AUTONÓMICA}

Después de examinar el papel de los recursos tributarios (impuestos cedidos e impuestos propios) en el sistema de financiación y de comentar los principales problemas que plantean en la actualidad, vamos a comentar, aunque sea brevemente, otras novedades que introduce el Estatuto de Autonomía para Andalucía recientemente aprobado en materia de financiación autonómica. El nuevo Estatuto contiene una regulación mucho más detallada que el antiguo sobre la Hacienda de la Comunidad Autónoma porque dedica a esta cuestión el Capítulo III del Título VI, que abarca desde los artículos 175 al 194.

La regulación de la Hacienda de la Comunidad se inicia en el artículo 175 con una enumeración de los principios generales que supone una mejora sustancial respecto de lo previsto en el Estatuto anterior. Allí se citan los principios constitucionales básicos de la financiación autonómica como son el de autonomía financiera, solidaridad y coordinación. A ellos se añaden otros principios como son: igualdad en el acceso y prestación de servicios y bienes públicos; suficiencia financiera que según se indica atenderá a la población real efectiva y en su caso a la protegida, así como a su evolución; garantía de financiación de los servicios de educación, sanidad y otros servicios sociales esenciales del estado de bienestar para alcanzar niveles similares en el conjunto del Estado siempre que se lleve a cabo un esfuerzo fiscal similar; responsabilidad fiscal, de acuerdo con los principios constitucionales de generalidad, equidad, progresividad, capacidad económica, coordinación y transparencia en las relaciones fiscales y financieras entre las Administraciones Públicas; lealtad institucional, coordinación (que se repite hasta en tres ocasiones en el precepto que estamos comentando) y colaboración con la Hacienda estatal y con las restantes haciendas públicas; nivelación de los servicios a que se refiere el artículo 158.1 de la Constitución; libre definición del destino y volumen del gasto público para la prestación de los servicios a su cargo, sin perjuicio de las exigencias de estabilidad presupuestaria; prudencia financiera y austeridad y participación mediante relaciones multilaterales en los organismos que proceda, relacionados con la financiación autonómica.

Esta enumeración de principios generales de la Hacienda de la Comunidad Autónoma se completa con el artículo 179 del nuevo Estatuto que contiene los principios rectores de la potestad tributaria. Después de recordar que dicha potestad para establecer tributos y recargos corresponde al Parlamento de la Comunidad, este precepto dispone que la misma se ejercerá con arreglo a los principios constitucionales de justicia material de los tributos del artículo 
31.1 de la Constitución que son: capacidad económica, justicia, generalidad, igualdad, equitativa distribución de la carga tributaria, progresividad y no confiscatoriedad. Por otra parte, este artículo 179 contiene otra novedad importante que no aparece en otros Estatutos ya aprobados ni tampoco en los proyectos que se están tramitando actualmente en las Cortes Generales. En concreto se alude en su apartado 2 a la función extrafiscal de los tributos cuando se afirma que "podrán ser instrumentos de política económica en orden a la consecución de un elevado nivel de progreso, cohesión, protección ambiental y bienestar social". En particular queremos destacar la referencia que se hace a la protección ambiental, porque Andalucía ha sido pionera en el establecimiento de tributos ambientales.

Actualmente se están aplicando en Andalucía cuatro tributos ambientales: impuesto sobre emisiones de gases a la atmósfera, impuesto sobre vertidos al litoral, impuesto sobre depósito de residuos radiactivos e impuesto sobre depósito de residuos peligrosos. Fueron creados por la Ley 18/2003, por la que se aprueban medidas fiscales y administrativas. Inicialmente se pensó en incluirlos en una Ley General de Fiscalidad Ambiental, pero finalmente razones de calendario obligaron a incluirlos en la citada Ley de acompañamiento a los Presupuestos. Pero el nuevo Estatuto, retoma de nuevo la idea de aprobar una Ley General de Fiscalidad Ambiental, hasta el punto de que su artículo 206, en su apartado 2, contiene una previsión que entendemos que constituye un indudable acierto al disponer que: "Una ley del Parlamento de Andalucía regulará medidas de fiscalidad ecológica, preventivas, correctoras y compensatorias del daño ambiental en el marco de la Ley Orgánica a que se refiere el artículo 157.3 de la Constitución española". Cuando se desarrolle esta previsión estatutaria Andalucía pasará a convertirse en la primera Comunidad en aprobar una Ley de Fiscalidad Ambiental.

Otra novedad importante que introduce el nuevo Estatuto es la creación de una Agencia Tributaria Andaluza. El artículo 181 del nuevo Estatuto, que está inspirado en el artículo 204 del Estatuto catalán, dispone en su apartado 2 que corresponderá a dicha Agencia, en primer lugar, la gestión, liquidación, recaudación e inspección de todos los tributos propios. En segundo lugar, y por delegación del Estado, también se encomendará a dicha Agencia la gestión, liquidación, recaudación e inspección de los tributos estatales totalmente cedidos a la Junta de Andalucía. En tercer término, por lo que respecta a los demás impuestos cedidos cuya gestión corresponde a la Agencia Estatal de Administración Tributaria (es decir, el Impuesto sobre la Renta de las Personas Físicas, el Impuesto sobre el Valor Añadido y los Impuestos Especiales a excepción del Impuesto sobre Determinados Medios de Transporte y el de Ven- 
tas Minoristas de Determinados Hidrocarburos) el párrafo 2 del apartado 2 de dicho artículo 181 dispone que "podrá establecerse un régimen de colaboración para su gestión compartida cuando así lo exija la naturaleza del tributo". A tal efecto, prosigue diciendo el precepto que "se constituirá en el ámbito de la Comunidad Autónoma un consorcio con participación paritaria de la Administración tributaria estatal", añadiéndose en su apartado 3, en esta misma línea, que la Comunidad Autónoma participará, en la forma que se determine "en los organismos tributarios del Estado responsables de la gestión, liquidación, recaudación e inspección de los tributos estatales cedidos parcialmente”. En relación con estos tributos, el apartado 3 del artículo 180 del Estatuto andaluz contempla la posibilidad de que la Comunidad Autónoma pueda recibir del Estado la delegación de la gestión, liquidación, recaudación e inspección de dichos tributos.

Este precepto tiene su antecedente en el Estatuto catalán que en su artículo 204 contempla la posibilidad de que la Administración tributaria de la Generalidad se encargue por delegación de la gestión, recaudación, liquidación e inspección de estos impuestos estatales cedidos recaudados en Cataluña, estableciendo para ello el compromiso de creación en el plazo de dos años de un Consorcio o ente equivalente en el que participarán de forma paritaria la Agencia Estatal de Administración Tributaria y la Agencia Tributaria de Cataluña. Este compromiso no estaba previsto en la versión original del Estatuto sino que se incorporó durante la fase de tramitación parlamentaria del Estatuto catalán, inspirándose en lo dispuesto en la disposición adicional segunda del Proyecto de Estatuto de Autonomía de la Comunidad de Canarias que en ese momento estaba en fase de presentación de enmiendas.

La Generalidad ha aprobado recientemente el Proyecto de Ley de creación de la Agencia Tributaria de Cataluña (aparece publicado en el Boletín Oficial del Parlamento de Cataluña núm. 31, de 12 de febrero de 2007). Su artículo 2, que se encarga de enumerar las funciones que le corresponden, ha dado lugar a una interesante polémica entre la Generalidad de Cataluña y el Ministerio de Economía Hacienda sobre las competencias de este consorcio. En opinión de la Generalidad de Cataluña para cumplir escrupulosamente lo que dispone el artículo 204 del Estatuto catalán este consorcio debería gestionar no sólo el Impuesto sobre la Renta sino también el Impuesto sobre el Valor Añadido. En cambio, el Ministerio de Economía y Hacienda entiende que las competencias de este consorcio deben limitarse al Impuesto sobre la Renta.

Volviendo al Estatuto andaluz hay que subrayar también como novedad que el artículo 181 dispone en su apartado 4 que la Administración Tributaria 
de Andalucía podrá asumir, por delegación, la gestión tributaria en relación con los tributos locales. De esta forma se prevé la posibilidad de que la Administración tributaria autonómica se ocupe de lo que actualmente vienen haciendo algunos organismos dependientes de las Diputaciones Provinciales.

En relación con las Entidades Locales hay otro precepto que introduce un cambio que nos parece de gran importancia. Se trata del artículo 192 que establece el compromiso de aprobación por ley de la participación de las Entidades Locales en los tributos de la Comunidad Autónoma a través de un fondo de nivelación municipal de carácter incondicionado.

Otra norma que merece ser citada en este repaso por las normas que regulan la financiación de la Comunidad Autónoma en el Estatuto andaluz es el artículo 183.5, que al regular las relaciones financieras entre la Comunidad y la Administración Tributaria del Estado establece una garantía de compensación en caso de reforma del sistema tributario que implique supresión de tributos o variación de los ingresos que percibe la Comunidad. Conviene advertir que el artículo 59 del Estatuto anterior, aprobado por Ley Orgánica 6/1981, de 30 de diciembre, ya establecía que en el caso de que como consecuencia de una reforma o modificación del sistema tributario estatal resultase una "variación sensible de aquellos ingresos de la Comunidad Autónoma que dependen de los tributos estatales", el Estado debía adoptar, de acuerdo con la Comunidad Autónoma, las medidas de compensación oportuna. En el nuevo Estatuto, aparte de que desaparece el término "sensible", que podría suponer un obstáculo a la posibilidad de articular las oportunas medidas de compensación, se refuerza la garantía de la Comunidad a percibir esa compensación ya que se dice literalmente que Andalucía tiene "derecho" a que el Estado adopte dichas medidas para que la Comunidad "no vea reducidas ni menguadas las posibilidades de desarrollo de sus competencias ni de su crecimiento futuro".

Por otra parte, se añade en este mismo precepto que estamos comentando otro aspecto novedoso cuando se establece que, de acuerdo con el principio de lealtad institucional, se valorará el impacto financiero, positivo o negativo, que las disposiciones generales aprobadas por el Estado tengan sobre la Comunidad Autónoma o bien que las aprobadas por la Comunidad Autónoma tengan sobre el Estado, en un período de tiempo determinado "en forma de una variación de las necesidades de gasto o de la capacidad fiscal, con la finalidad de establecer los mecanismos de ajuste necesarios."

También nos interesa comentar en este análisis de la regulación de la financiación autonómica contenida en el nuevo Estatuto su artículo 182. Inspi- 
rándose en el artículo 205 del Estatuto catalán, el artículo 182 del Estatuto andaluz dispone que la Comunidad Autónoma asumirá, por medio de sus propios órganos económico-administrativos, la revisión en vía administrativa de las reclamaciones que los contribuyentes interpongan contra los actos de gestión tributaria dictados por la Agencia Tributaria andaluza, incluso, con respecto a los tributos cedidos por el Estado. Actualmente, la competencia para la revisión de los actos de gestión tributaria dictados por la Administración autonómica corresponde a los Tribunales Económico-Administrativos Regionales, que son órganos administrativos (y no auténticos tribunales de justicia a pesar de su denominación) integrados en la Administración General del Estado. A partir de la entrada en vigor del nuevo Estatuto esta situación, que en nuestra opinión podía calificarse de irregular, cambiará porque las competencias de revisión serán asumidas por órganos económico-administrativos de la Comunidad Autónoma aunque, como bien se advierte en el inciso final del primer párrafo del artículo 182, "sin perjuicio de las competencias en materia de unificación de criterio que le corresponden a la Administración General del Estado". Y en su segundo párrafo se añade que a estos efectos, la Junta de Andalucía y la Administración General del Estado podrán "acordar los mecanismos de compensación que sean precisos para el adecuado ejercicio de las funciones de revisión en vía económico-administrativa”.

El último precepto en el que nos vamos a detener en este apartado es la disposición adicional tercera del Estatuto andaluz que se refiere a las inversiones en Andalucía. En su apartado 1 se dispone que el gasto de inversión del Estado con destino a Andalucía "deberá garantizar de forma efectiva el equilibrio territorial, en los términos del artículo 138.1 y 2 de la Constitución”. Pero sobre todo nos interesa detenernos en su apartado 2 en el que se establece el compromiso del Estado de destinar a Andalucía una inversión que "será equivalente al peso de la población andaluza sobre el conjunto del Estado para un período de siete años". Con esta finalidad se constituirá una Comisión integrada por representantes de la Administración estatal y autonómica. Se trata de una norma con un contenido que recuerda a la disposición adicional tercera del Estatuto catalán que bajo el título "Inversiones en infraestructuras" establece que la inversión del Estado en Cataluña en infraestructuras, excluido el Fondo de Compensación Interterritorial, "se equiparará a la participación relativa del producto interior bruto de Cataluña con relación al producto interior bruto del Estado para un período de siete años". En ambos casos estamos ante disposiciones en las que el Estado se compromete a un determinado volumen de inversiones en una Comunidad Autónoma.

Inspirándose en esta disposición del Estatuto catalán el Proyecto de Estatuto aprobado por el Parlamento de Baleares y remitido a las Cortes Genera- 
les (véase Boletín Oficial de las Cortes Generales, Congreso de los Diputados, Núm. B-251-1 de 30 de junio de 2006) contenía una norma en virtud de la cual el Estado tendría que dedicar en los próximos diez años el 2,5 por 100 de sus inversiones a Baleares, y que el monto total no podrá ser inferior a tres mil millones de euros. Y todo ello para compensar los déficits acumulados por la falta de inversiones públicas en las islas por la insuficiente dotación económica en materia de educación, sanidad y servicios sociales y por el constante incremento de la población.

Durante la tramitación parlamentaria del Estatuto de Baleares en el Congreso de los Diputados los dos principales partidos políticos acordaron modificar el contenido de la disposición transitoria novena de dicho Estatuto que en la versión finalmente aprobada por esta Cámara (véase el Boletín Oficial de las Cortes Generales, Congreso de los Diputados Núm. B-251-16, de 29 de diciembre de 2006) dispone en su apartado 1 que mientras "las Cortes Generales, en aplicación de lo previsto en la Disposición adicional sexta no aprueben la modificación de la Ley 30/1998, de 29 de julio, del Régimen Especial de las Islas Baleares y, en todo caso, en un plazo no superior a siete años, la inversión del Estado se establecerá atendiendo a la inversión media per cápita realizada en las Comunidades Autónomas de régimen común, determinada con arreglo a la normativa estatal, homogeneizando las actuaciones inversoras realizadas en dichas comunidades para permitir su comparabilidad y teniendo presentes las circunstancias derivadas de los hechos diferenciales y excepcionales de la Comunidad Autónoma de las Islas Baleares con incidencia en la cuantificación de la inversión pública.”

También contiene una disposición similar el Proyecto de Estatuto de Aragón que actualmente se está tramitando en las Cortes Generales (véase el Boletín Oficial de las Cortes Generales, Congreso de los Diputados, Núm. B-253-1 de 8 de septiembre de 2006). Nos referimos a su Disposición adicional sexta que establece que para la fijación de las inversiones del Estado en Aragón en infraestructuras, "se tendrán en consideración, con carácter prioritario, la superficie del territorio, los costes diferenciales de construcción derivados de la orografía, así como su condición de comunidad fronteriza, y se incorporarán criterios de equilibrio territorial a favor de las zonas más despobladas."

El último Proyecto de Estatuto de Autonomía que ha entrado en las Cortes Generales también incluye una disposición similar a las que estamos comentando. Nos referimos a la disposición adicional única del Proyecto de Estatuto remitido por las Cortes de Castilla-La Mancha (Boletin Oficial de las Cortes Generales, Congreso de los Diputados, Núm. B-276-1 de 09 de febrero de 2007) 
que dispone que la inversión anual en infraestructuras del Estado en esta Comunidad Autónoma, excluido el Fondo de Compensación Interterritorial, "será al menos equivalente al porcentaje medio que resulte de considerar el peso de la población regional sobre el conjunto del Estado, la participación relativa del producto interior bruto de Castilla-La Mancha con relación al del Estado y el porcentaje que representa la extensión territorial de la Comunidad Autónoma sobre la extensión territorial del Estado." También debemos citar en este sentido la Disposición transitoria tercera del Proyecto de Estatuto castellano-manchego que establece que con objeto de acelerar el proceso de convergencia, y en tanto el producto interior bruto por habitante de Castilla-La Mancha se equipare a la media por habitante española, "el Estado realizará inversiones complementarias en Castilla-La Mancha por un importe equivalente al uno por ciento del producto interior bruto regional. Dichas inversiones tendrán carácter extraordinario y serán adicionales a las que correspondan conforme a lo establecido en la disposición adicional."

Todas estas disposiciones que hemos citado establecen con distintos matices el compromiso del Estado de realizar determinadas inversiones en cada Comunidad Autónoma. La cuestión que se plantea en relación con estas normas y que a nuestro juicio merecería desde luego un estudio más detenido, es si una Comunidad Autónoma a través de su Estatuto de Autonomía puede decidir lo que el Estado tiene que invertir en su territorio.

\section{CONSIDERACIONES SOBRE LA “DEUDA HISTÓRICA” A LA LUZ DE LA SENTENCIA DEL TRIBUNAL CONSTITUCIONAL $13 / 2007$}

El último apartado de este trabajo está dedicado al análisis de una disposición estatutaria que ha generado bastante polémica en los últimos años. Se trata de la disposición adicional segunda del Estatuto de Autonomía aprobado por Ley Orgánica 6/1981, que ha dado lugar en Andalucía a reivindicaciones en torno a lo que se ha llamado "deuda histórica". El nuevo Estatuto contiene una disposición similar como ahora veremos.

La disposición adicional segunda del Estatuto de 1981 decía así:

"1. Dadas las circunstancias socio-económicas de Andalucía, que impiden la prestación de un nivel mínimo en alguno o algunos de los servicios efectivamente transferidos, los Presupuestos Generales del Estado consignarán, con especificación de su destino y como fuentes excepcionales de financiación, 
unas asignaciones complementarias para garantizar la consecución de dicho nivel mínimo.

2. Los criterios, alcance y cuantía de dichas asignaciones excepcionales serán fijados para cada ejercicio por la Comisión Mixta paritaria Estado-Comunidad Autónoma a que se hace referencia en el apartado 2 de la Disposición transitoria sexta."

Estas asignaciones especiales previstas únicamente en el Estatuto andaluz y el extremeño constituyen una concreción de las previstas en el artículo 158.1 de la Constitución para garantizar el nivel mínimo en la prestación de servicios públicos fundamentales. Estas asignaciones, desarrolladas por el artículo 15 LOFCA, se caracterizan por su carácter complementario por lo que las Comunidades Autónomas sólo podrían ser beneficiarias de ellas en el supuesto de que los recursos obtenidos a través de las demás fuentes de financiación resultasen insuficientes para garantizar ese nivel mínimo. Además, se trata de asignaciones condicionadas y con un marcado carácter finalista, pues el artículo 15.2 LOFCA exige que aparezcan consignadas en los Presupuestos Generales del Estado "con especificación de su destino" y que se destinen en todo caso a financiar la prestación de servicios públicos fundamentales. La primera vez que se establecieron estas asignaciones fue en la Ley 12/1996, de 30 de diciembre, que aprobó los Presupuestos Generales del Estado para 1997. Su Sección 32 consignó con este objetivo un crédito por importe de $10.000 \mathrm{mi}$ llones de pesetas. Al año siguiente, la Ley 65/1997, de 30 de diciembre, de Presupuestos Generales del Estado para 1998, incrementó en 2.000 millones de pesetas la dotación presupuestaria destinada a hacer efectivas estas asignaciones. A las dificultades políticas para poner de acuerdo a las Comunidades Autónomas con el Estado se han sumado la falta de concreción sobre los servicios públicos que se pueden calificar fundamentales y sobre qué ha de entenderse por nivel mínimo en la prestación de dichos servicios.

La disposición adicional segunda del nuevo Estatuto andaluz sigue contemplando la necesidad de consignar estas asignaciones en los Presupuestos Generales del Estado, aunque introduciendo una importante novedad como es la fijación de un plazo de dieciocho meses para negociar y cuantificar la deuda y tres años para su pago a partir de la entrada en vigor del mismo. En concreto, la disposición adicional segunda del nuevo Estatuto dice así:

"1. La disposición adicional segunda del Estatuto de Autonomía aprobado por Ley Orgánica 6/1981, de 30 de diciembre, determinó que los Presupuestos Generales del Estado debían consignar, con especificación de su des- 
tino y como fuentes excepcionales de financiación, unas asignaciones complementarias para hacer frente a las circunstancias socio-económicas de Andalucía.

2. La Comisión Mixta de Transferencias Administración del Estado-Comunidad Autónoma de Andalucía aprobó el Acuerdo suscrito entre la Administración del Estado y la citada Comunidad Autónoma, percibiendo esta última un anticipo a cuenta de las citadas asignaciones.

En dicho Acuerdo se recogía la existencia de un acuerdo parcial sobre una posible metodología a emplear en la determinación de los criterios, alcance y cuantía de las asignaciones excepcionales a que se refiere el apartado anterior.

3. En el caso de que, a la fecha de aprobación del presente Estatuto, no hayan sido determinadas y canceladas en su totalidad las cuantías derivadas de lo señalado en el apartado anterior, la Comisión Mixta establecerá, en el plazo de dieciocho meses, los criterios, alcance y cuantía que conduzcan a la ejecución definitiva del mismo. En este supuesto, la aplicación de los acuerdos adoptados se realizará en un plazo de tres años a partir de la entrada en vigor del presente Estatuto.

4. En el procedimiento establecido en el apartado anterior, la Administración General del Estado podrá otorgar anticipos a cuenta”.

En relación con la "deuda histórica" es preciso citar la Sentencia del Tribunal Constitucional 13/2007, de 18 de enero, que ha desestimado el recurso presentado por el Parlamento andaluz contra la Ley de Presupuestos Generales del Estado de 1998. Dicho recurso se basó en dos argumentos: el primero, que se había tomado como base para la financiación autonómica el censo de 1991 y no el actualizado de 1995 (mayor) y el segundo la no inclusión de una partida para pagar la "deuda histórica" con Andalucía. Por lo que respecta al primer argumento, el Tribunal lo desestima por entender que "no es suficiente la mera discrepancia política para tachar a la norma de arbitraria" y porque "no puede apreciarse que carezca de toda justificación razonable la opción del legislador, ya que, aun cuando pueda discreparse de ella, no cabe duda de que no responde a capricho o mero voluntarismo, al ser consecuencia de la inexistencia, en el momento de aprobarse el nuevo sistema de financiación, de un censo oficial diferente”. Según el Tribunal la utilización del censo de 1991 "entra dentro del margen de configuración del que goza el legislador en este ámbito”. Aunque no cabe duda de que existían otras alterna- 
tivas pudiendo haber concretado el legislador la variable población de acuerdo con criterios diferentes (tomando como referencia, por ejemplo, los padrones municipales, los censos electorales u otros índices acreditativos con fiabilidad de la población de hecho) el Tribunal concluye que a él no le corresponde "interferirse en ese margen de apreciación ni examinar la oportunidad de la medida legal para decidir si es la más adecuada o la mejor de las posibles, sino sólo comprobar si no se ha sobrepasado ese margen de libertad creando una diferencia de trato irracional o arbitraria”. Hay un voto particular que discrepa de esta interpretación del Tribunal firmado por el Magistrado Pérez Tremps, quien considera que el legislador no debería haber ignorado el censo de 1995 pues "no puede entrar en el margen de configuración del legislador ni en su necesaria discrecionalidad para fijar opciones políticas ignorar un dato oficial".

En relación con la segunda alegación del Parlamento andaluz, es decir, el incumplimiento por parte del Estado de la previsión recogida en la disposición adicional segunda del Estatuto de Autonomía de Andalucía, el supremo intérprete de la Constitución comienza en su Fundamento Jurídico 11 concretando que "el problema que se somete a nuestra consideración desde esta última perspectiva no es si la cuantía consignada en la Ley de presupuestos es o no suficiente para atender la necesaria, en su caso, nivelación de servicios públicos fundamentales, ni tampoco si la misma ha sido o no efectivamente liquidada, sino única y exclusivamente si las asignaciones a las que hace referencia el artículo 15 LOFCA (y que el Parlamento recurrente reconoce expresamente que han sido consignadas en el instrumento presupuestario correspondiente al ejercicio 1998) son algo distinto de aquéllas a las que se refiere la disposición adicional segunda del Estatuto de Autonomía para Andalucía, habida cuenta que no existe reconocimiento o consignación de cantidad alguna al amparo de esta última disposición estatutaria en la citada Ley 65/1997”.

A juicio del Tribunal estamos en presencia de un instrumento de financiación de las Comunidades Autónomas "de carácter extraordinario, que únicamente procede en aquellos supuestos en los que los restantes recursos o instrumentos dirigidos a la financiación de las Comunidades Autónomas (en particular, los tributos cedidos y la participación en los tributos del Estado) resulten insuficientes para garantizar la consecución de un nivel mínimo en la prestación de aquellos servicios públicos que tengan la consideración de fundamentales".

El Constitucional reconoce la «legitimidad constitucional» de las asignaciones complementarias previstas en la disposición adicional segunda como 
un instrumento «excepcional» para la consecución de un nivel mínimo en la prestación de determinados servicios» en Andalucía. Ahora bien, después de reconocer la legitimidad de esta singularidad del Estatuto andaluz, el Tribunal matiza que "no puede aceptarse que las asignaciones a las que se refiere el Estatuto de Andalucía sean un recurso que el Estado deba consignar obligatoriamente en los presupuestos generales de cada ejercicio económico". Según el Tribunal, "esta interpretación no se compadece, ni con el carácter excepcional o extraordinario de este mecanismo de financiación, ni con el hecho de que, tal y como sucedía en relación con la participación en los ingresos del Estado, es a este último a quien corresponde en exclusiva, atendiendo a la totalidad de los instrumentos para la financiación de las Comunidades Autónomas, a las necesidades de cada una de éstas y a las posibilidades reales del sistema financiero del Estado, decidir si procede dotar, en su caso, y en qué cuantía aquellas asignaciones en virtud de la competencia exclusiva que sobre la materia le atribuye el art. 149.1.14 CE (hacienda general)".

La primera conclusión que se extrae de este fallo es que el Tribunal Constitucional reconoce la singularidad del Estatuto andaluz y la existencia de una deuda. En segundo lugar, el Tribunal matiza que aunque este mecanismo de financiación excepcional sea perfectamente constitucional, ello no implica que el Estado tenga que consignar obligatoriamente en los Presupuestos estas asignaciones si previamente no se ha llegado a un acuerdo sobre las mismas entre el Estado y la Comunidad Autónoma en la correspondiente Comisión Mixta. Y en tercer término, el Tribunal advierte que si bien la decisión de establecer dicha dotación le corresponde al Estado "su actuación debe resultar presidida por el principio de lealtad constitucional que, como hemos afirmado en un caso que presenta alguna similitud con el ahora sometido a nuestro enjuiciamiento, "obliga a todos", y que impone que el Gobierno deba "extremar el celo por llegar a acuerdos en la Comisión Mixta" (STC 209/1990, de 20 de diciembre, FJ 4)".

\section{BIBLIOGRAFÍA}

ADAME MARTÍNEZ, F.D., El sistema de financiación de las Comunidades Autónomas de régimen general, Editorial Comares, 1998.

CALVO ORTEGA, R., "La financiación posible de las CCAA (En torno al nuevo modelo)”, Nueva Fiscalidad, núm. 1, 2002. 
CAYÓN GALIARDO, A., "Las competencias normativas de las Comunidades Autónomas sobre los tributos cedidos", Alcabala, Revista de Hacienda Pública de Andalucía, núm. 28, 2/2001.

COMISIÓN PARA EL ESTUDIO Y PROPUESTA DE UN NUEVO SISTEMA DE FINANCIACIÓN DE LAS COMUNIDADES AUTÓNOMAS APLICABLE A PARTIR DE 2002, Informe sobre la reforma del sistema de financiación autonómica, Ministerio de Hacienda, Instituto de Estudios Fiscales, 2002.

GONZÁLEZ GONZÁLEZ, A.I., "El nuevo sistema de financiación de las Comunidades de régimen común: principales novedades”, Información Fiscal, núm. 53, 2002.

LASARTE ÁLVAREZ, J. (como Director), Estudios jurídicos sobre la reforma del sistema de financiación autonómica, Instituto de Estudios Fiscales. Contiene trabajos de ADAME Martínez, F., LASARTE ÁLVAREZ, J., MARTÍN FERNÁNDEZ, J., MARTÍN QUERALT, J., RAMOS PRIETO, J., y SÁNCHEZ PEDROCHE, J.

LASARTE ÁLVAREZ, J. (como Director), El debate sobre el sistema de financiación autonómica, Jornadas conmemorativas del XX Aniversario del Estatuto de Autonomía para Andalucía, Parlamento de Andalucía.

LASARTE ÁLVAREZ, J., "El nuevo modelo de financiación autonómica. Aspectos jurídicos generales”, Revista de Estudios Regionales, núm. 66, 2003.

PÉREZ DE AYALA, J.L. (como Director), Estudios del sistema de financiación autonómica, Edersa e Instituto de Estudios Fiscales, 2002. Contiene trabajos de BARRUSO, B., CAÑA, F., GOROSPE, J.I., PÉREZ DE AYALA, J.L., PÉREZ DE AYALA BECERRIL, M., SIMÓN, M., y VILLAR, M.

QUINTANA FERRER, E., Los recursos participativos en el marco de la articulación entre las Haciendas autonómica y estatal, Generalidad de Cataluña y Editorial Tirant lo Blanch, 2001.

RAMOS PRIETO, J., La cesión de impuestos del Estado a las Comunidades Autónomas, Editorial Comares, 2001.

SALINAS JIMÉNEZ, J. (como Director), El nuevo modelo de financiación autonómica, Instituto de Estudios Fiscales, 2002. Contiene trabajos de CANTARERO, D., MONASTERIO, C., URBANOS, R.M., UTRILLA, A., y VALLÉS, J.

SEVILLA SEGURA, J.V., Las claves de la financiación autonómica, Crítica, 2001. 


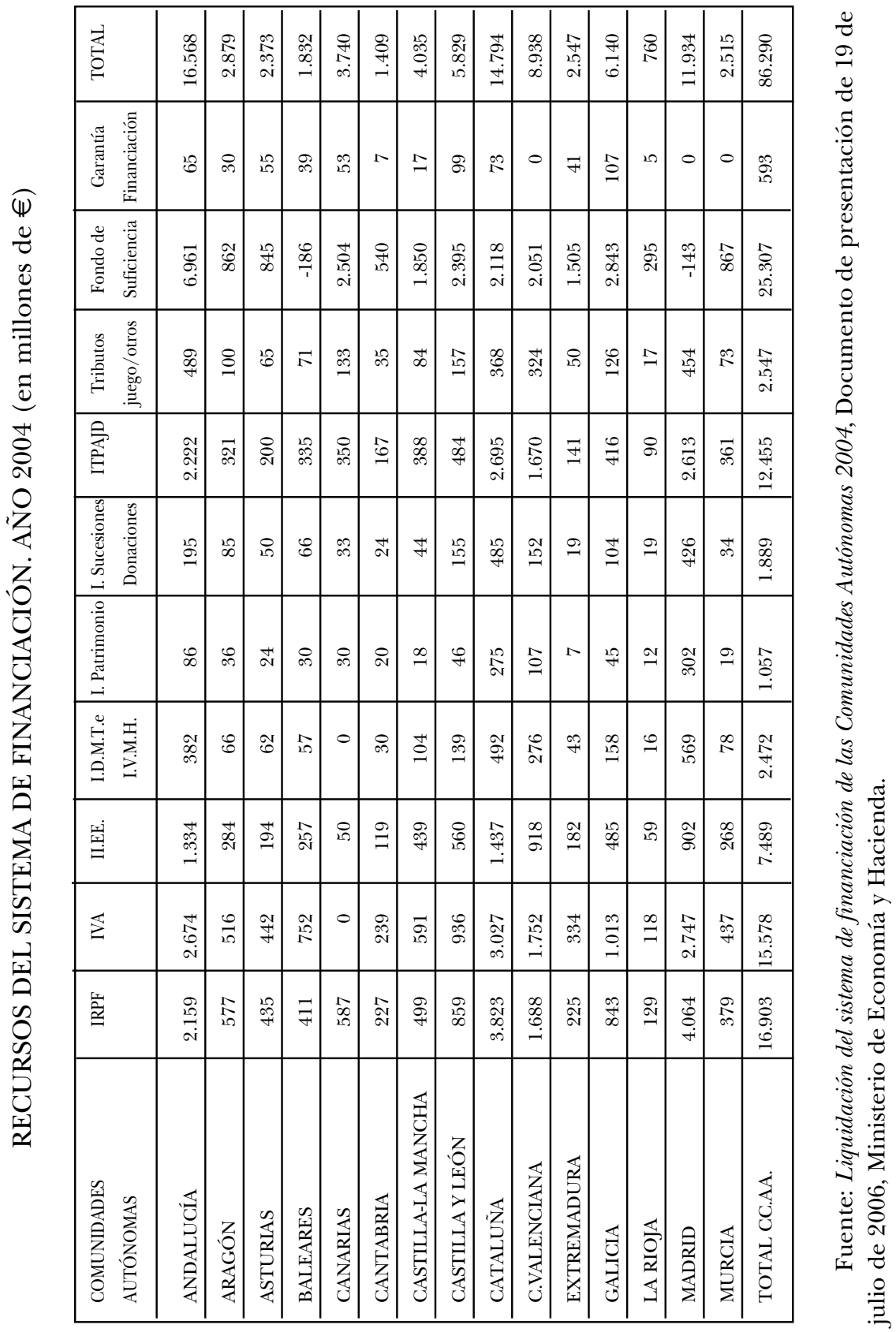

